\title{
Canalizos y tajeas, dos sistemas de captación de agua mediante galerías subterráneas en las altiplanicies granadinas. Andalucía Oriental
}

\author{
Canalizos and tajeas, two systems of water collection using underground \\ water galleries in the high plains of Granada. Eastern Andalusia
}

\author{
Maryelle Bertrand † \\ José R. Sánchez Viciana *
}

\begin{abstract}
RESUMEN
Estos primeros datos sobre las galerías subterráneas de captación de agua de las altiplanicies granadinas forman parte de una investigación actualmente en curso sobre los sistemas de regadío de las Hoyas de Guadix y de Baza, en Andalucía Oriental. Uno de sus principales objetivos es intentar establecer el orden cronológico de la implantación de las diversas redes y de sus transformaciones, utilizando de manera regresiva las encuestas etnológicas, el estudio documental y la arqueología !
\end{abstract}

Palabras clave: Qanat, galería drenante, tajea, acequia, regadío, hidráulica.

Las dos comarcas vecinas de Baza y Guadix, encaramadas entre los 900 y 1000 m de altitud y enmarcadas por altas montañas que culminan a más de 3000 m., como Sierra Nevada y Sierra de Baza, presentan un clima similar, continental mediterráneo con precipitaciones medias de 300 a 350 mm. (600 a 700 mm. en las zonas de montaña) pudiendo descender a los 200 ó 250 mm. en los años secos (Fig. I). Presentan, no obstante, recursos hídricos y técnicas de captación diferentes para asegurar el regadío de sus territorios.

Los qanats, tal como los encontramos en la comarca de Baza, han sido objeto de múltiples

\begin{abstract}
This prelimenary data about water collection from underground water galleries in the high plains of Granada forms part of a wider study now in progress about the irrigation systems in the Guadix-Baza basin in eastern Andalusia. One of the main objectives of this study is to establish the cronological order of the implantation of the diverse water networks and their transformations, using historical etnological surveys, documented studies and arqueology.
\end{abstract}

Key Words: Qanat, drainage systems, underground water galleries, khettara, karez, irrigation canal, hydraulic.

estudios. Los sistemas de captación de aguas subálveas, mediante cimbras y tajeas, como se les denominan en Guadix, difícilmente detectables, mal documentados, no visibles en foto aérea ni a menudo sobre el terreno y a veces confundidos con los qanats, no han recibido quizás la atención que merecen.

\section{LOS CANALIZOS DE BAZA}

La región de Baza dispone de importantes surgencias naturales que alimentan las redes de regadío de la ciudad y de pueblos de considerable tamaño como Caniles y Zújar, pero

\footnotetext{
† La Revista AyTM quiere con la publicación de este trabajo unirse a los homenajes a la autora recientemente fallecida. * Arqueólogo

I. Este trabajo fue presentado en el Coloquio Internacional Las galerías de captación en la Europa mediterránea. Una aproximación pluridisciplinar, Madrid 4-6 de junio de 200I, Casa de Velázquez, Fundación Canal de Isabel II. Fue redactado en francés a finales de ese mismo año y no pudo tomar en cuenta diversos trabajos sobre este mismo tema realizados desde entonces. El texto que ahora se presenta es su traducción.
} 
también de cursos de agua permanentes de notable caudal, como son los ríos Guardal, Guadiana Menor y Cúllar, que permiten la irrigación de las mejores tierras mediante presas de derivación construidas o temporales (azudes). Por el contrario, el noreste de la comarca, al pie de las Sierras de Orce y Las Estancias, desprovisto de aguas superficiales, es el dominio de los qanats que reciben aquí el nombre de Canalizos (sectores de El Margen y Cúllar de Baza) (Fig. 2). Su número, en el conjunto de la zona, es difícil de determinar, pudiendo ser del orden de doscientos o trescientos, quizás más. A semejanza de lo ocurrido en otros lugares, la perforación de pozos ha provocado una bajada drástica del nivel de la capa freática y la pérdida en la actualidad de la mayor parte de estos sistemas.

Estos qanats, en su conjunto, son de pequeñas dimensiones, desde un centenar de metros hasta 1,5 Km. para los más largos. Sus pozos madre, en la mayor parte de los casos, alcanzan profundidades de 5 a $15 \mathrm{~m}$, y 20 a $30 \mathrm{~m}$ en algunos ejemplares. Su aforo es bajo, de algunos litros por segundo. Cada uno de ellos está asociado a una balsa y alimenta, según los casos, una vivienda, un cortijo o como mucho una cortijada formada por una aglomeración dispersa de viviendas troglodíticas (Fig. 3).

Desde un punto de vista histórico, el estudio etnográfico y el documental muestran claramente el origen subactual, o atribuible al periodo moderno, de la mayor parte de ellos. Hemos podido encontrar uno de los últimos especialistas en la excavación de qanats de esta región, un hombre de unos sesenta años que aprendió el oficio de su padre y de su abuelo. Al igual que ellos, también fue pocero y «maestro de pico de picar cuevas», especialista en la excavación de viviendas troglodíticas, forma de hábitat rural y suburbano tradicional en toda esta región ${ }^{2}$. Utilizaba técnicas de cálculo y nivelación muy similares a las conocidas desde el medievo, con cuerdas, nudos, palos suspendidos y la sombra del cordel de la plomada proyectada por un candil de aceite, para mantener la rectitud de la galería. Sin embargo, en su tiempo la perfección técnica de los más antiguos qanats ya se había perdido (frecuentes errores de cálculo, gran proximidad de los pozos). Por razones de economía los comanditarios exigían muy a menudo la excavación de galerías muy bajas que debían ser excavadas de rodillas, haciendo aun más peligrosa su conexión con los pozos madre.

El periodo del siglo XIX / principios del XX se presenta, sin lugar a dudas, como uno de los más intensos en la excavación de qanats en esta región, ligado a una fuerte presión demográfica y a numerosas tentativas, a menudo abortadas, de puesta en explotación de tierras hasta entonces marginales.

Algunos datos referentes a momentos anteriores comienzan a aparecer en la documentación notarial de los ss. XVII-XVIII, relativos a la reconstrucción o a la excavación de nuevos sistemas, a iniciativa de grandes propietarios, de pequeños grupos de agricultores, o de un solo y pequeño explotador. Sin embargo, a medida que se avanza con el estudio documental regresivo, la posibilidad de encontrar eventuales qanats medievales se réduit à une peau de chagrin ${ }^{3}$.

Por otra parte se esbozan una serie de argumentos que parecen limitar aún más estas posibilidades.

En primer lugar la limitada vida de estas estructuras relativamente frágiles, excavadas en un terreno blando de margas, casi todas desprovistas de sostenimientos de sus entradas o de la parte superior de sus pozos, cuya supervivencia está ligada estrechamente a su mantenimiento permanente (Fig. 4). Un documento de 1877 nos da una idea de la capacidad de conserva-

\footnotetext{
2. Esta misma relación sistemática entre estas dos actividades de pocero y picador de cuevas ha podido ser constatada en la región de Guadix.

3. (Nota de traducción:) En referencia a la novela de Balzac, traducida en castellano con el título Piel de Zapa.
} 
ción ${ }^{4}$. Hace referencia a la excavación de un importante canalizo por una sociedad de 12 agricultores para paliar una disminución del caudal del río próximo de Cúllar ${ }^{5}$. Poco tiempo después, en 1893, tras un periodo menos seco, se produce un semiabandono del sistema, que ya no es mantenido por los diversos propietarios. Apenas 12 años después esta obra ha devenido prácticamente irrecuperable.

Con todo, algunos de los qanats de mayores dimensiones son de mejor factura y podrían ser más antiguos, como el del Cortijo de Soriano, considerado junto con otros como «canalizo de moros» por su perfección técnica, sus dimensiones relativamente importantes $(\mathrm{l} \mathrm{Km}$.) y la presencia de sostenimientos (muretes y pozos en piedra seca, cubierta de losas calcáreas). Sin embargo, el contexto arqueológico y la tipología de las cuevas de vivienda a las que está asociado indican, de nuevo, una atribución al periodo moderno (Fig. 5 y 6 ).

El estudio de la organización del poblamiento de la Baja Edad Media tampoco ofrece muchas esperanzas, con excepción quizás de algunos sistemas situados cerca de los principales pueblos. El tipo de hábitat abierto y muy disperso asociado a los qanats difícilmente puede corresponder a este periodo. La región de Baza, y más concretamente este sector oriental, se convirtió desde principios del s. XIII en una zona de frontera ásperamente disputada, sometida a incesantes razias y prácticamente vacía de poblamiento rural intercalar hasta su conquista definitiva por los cristianos en 1489. La población, en época nazarí, se presenta densamente agrupada en grandes alquerías alrededor de una pequeña fortaleza, como en Cúllar o Benamaurel. Los importantes cursos de agua que atraviesan las mejores tierras y permiten regar el territorio próximo de estos grandes pueblos eran ampliamente suficientes para cubrir las necesidades de la población (Fig. 7).
A pesar de sus sistemas de alimentación, por simples azudes, prácticamente todas las acequias de estas poblaciones presentan enormes redes subterráneas, provistas de largos túneles de varios cientos de metros, entrecortados por profundos pozos de aireación, muy similares a los qanats en cuanto a los cálculos de nivelación que su excavación necesita, como a sus técnicas de ejecución. Algunos de estos canales subterráneos, destinados a aumentar el perímetro irrigado y a proteger la acequia de la erosión en los meandros, son de época moderna, como es el caso de los del Barranco de Los Burgos. Otros parecen claramente medievales, como tendería a probarlo el canal subterráneo de la Acequia de Rasmal, reunido por un pozo de subida con las habitaciones superiores del conjunto troglodítico de los hábitats acantilados de Las Hafas de Benamaurel, fechables de finales del s. XII (Fig. 8) (BERTRAND, 1990). Ciertamente, la técnica era dominada en esta región durante la Edad Media, pero todo parece indicar que su utilización no era sino excepcionalmente necesaria.

Cabe señalar, cuando la necesidad se hace sentir, la ingeniosidad de ciertos sistemas como el del refugio acantilado de Los Algarbes de Gorafe, igualmente de época Almohade. Una acequia fue excavada en el interior del acantilado, a más de $50 \mathrm{~m}$ de altura, para captar dos puntos de infiltración kárstica con la finalidad de alimentar una pequeña cisterna (Fig. 9 y I0).

\section{LOS SISTEMAS DE CAPTACIÓN DE LA HOYA DE GUADIX: PRESAS, MINAS Y TAJEAS}

La Hoya de Guadix, presenta una imbricación de sistemas de irrigación y de captación más compleja que la de Baza. Las condiciones hidrogeológicas son aquí bastante diferentes y han dado lugar al desarrollo de otros tipos de galerías de captación, las tajeas. Los qanats,

4. Archivo Municipal de Benamaurel, Copia de acta notarial, El Algibe, 1906.

5. En esta fecha el qanat, dotado de una balsa, permite regar 2 fanegas por día. Los turnos establecidos, de I 5 días, permiten el riego de 7,5 Ha. 
por el contrario, están prácticamente ausentes, a excepción de tres pequeños ejemplares de origen moderno o subactual (Cortijo del Sacristán, Cortijo de La Tala).

Desde un punto de vista geomorfológico, la depresión de Guadix es un antiguo lago cuaternario, progresivamente colmatado por sedimentos provenientes de las grandes montañas que lo rodeaban por todas partes, como Sierra Nevada al sur o Sierra de Baza. Tras un probable basculamiento de origen tectónico, sus aguas se vacían para encontrar la red hidrográfica del valle del Guadiana Menor, situado más abajo, provocando un fenómeno de erosión remontante en las tierras de la altiplanicie y el encastramiento en cabecera de la red hidrográfica en la espesa capa de sedimentos que ocupaba el fondo de la Hoya.

Este fenómeno dio lugar a un escalonamiento de paisajes bien diferenciados, provistos de recursos hidráulicos superficiales y subterráneos igualmente muy diferentes:

- Los pies de monte, particularmente los de Sierra Nevada, están bañados por numerosos torrentes provenientes esencialmente de la fusión de las nieves. Sus aguas superficiales son casi íntegramente captadas por grandes sistemas de acequias que irrigan las tierras de las poblaciones del pie de monte y de la altiplanicie, totalmente desprovistas de aguas superficiales (Acequia de La Sierra, Acequias del Zenete). El resto desaparece inmediatamente en los aluviones (Fig. II y 12). Las grandes acequias de Sierra Nevada aseguran el riego permanente del piedemonte y de algunos de los pueblos de la altiplanicie y de las tierras bajas (regadío fijo). La mayor parte de la red tan solo funciona en primavera, para regar los cereales y las viñas en la altiplanicie y en ciertos barrancos (regadío eventual). El acuífero se alimenta, principalmente en invierno, por la percolación de una parte de las aguas provenientes de Sierra Nevada y en menor medida de Sierra de Baza, por infiltración directa de las aguas de lluvia y por la infiltración de las aguas de irrigación de la altiplanicie. Su nivel piezométrico se sitúa entre 1065 y 1000 m, a una profundidad de 30 a $80 \mathrm{~m}$ bajo el nivel de la altiplanicie (CASTILLO PÉREZ et alii, 1986a).

- La ruptura de pendiente entre la altiplanicie y el fondo de la depresión, ocupada por pequeños valles enmarcados por las tierras de badlands, permite el afloramiento de una multitud de pequeñas fuentes y surgencias naturales de la capa freática y de las aguas subálveas, a menudo de régimen intermitente, en el interior de ciertos barrancos y en el mismo lecho de los ríos. La captación de estas surgencias mediante presas permite, a veces, la instalación de un segundo conjunto de sistemas de regadío, en general de pequeño tamaño (valle medio del Alhama, valle de Paulenca).

Estas captaciones sucesivas y la rápida desaparición de las surgencias en los aluviones agotan totalmente los ríos del centro de la región durante prácticamente todo el año, con excepción de algunos meses de invierno durante los cuales el riego no es necesario. Es aquí, con todo, donde se sitúa la vega de la Hoya de Guadix que cubre en total más de $2000 \mathrm{Ha}$.

Hasta una fecha reciente, la práctica totalidad de esta vega era irrigada a partir de tajeas, galerías subterráneas que captan las aguas subálveas en los lechos secos de los ríos y ramblas. En los aluviones del Río Verde o Río de Guadix, al menos hasta los años 70, el nivel piezométrico se situaba efectivamente a profundidades fácilmente accesibles, de 2 a $15 \mathrm{~m}$.

\section{Las tajeas de la región de Guadix}

La denominación de tajea o a veces tejea, atajea, atejea, utilizada en la región de Guadix deriva de la palabra castellana de origen árabe «atarjea», que designa a la vez una galería construida para evacuación de aguas usadas y las galerías de drenaje de aguas subálveas (Fig. 13 y 14$)$.

El inventario de este tipo de galerías de captación está por completar para Andalucía Oriental. Desde la Hoya de Guadix, se las 
encuentra hacia el sureste en todo el pasillo de Fiñana hasta la ciudad de Almería. Aseguran una gran parte del regadío en el Río Izfalada (zona de Hueneja / La Huertezuela), en todo el valle alto del Río Instinción (Fiñana, Abla, Doña María), del valle del Andarax (Ragol, Instinción, etc.) (BERTRAND y CRESSIER, 1985), y en la vega de Almería. Igualmente se localizan en pequeños acuíferos aluviales costeros de las provincias de Granada y Almería. Entre estas cabe señalar la galería de captación antigua que alimenta la Acequia del Rey y la de Almansa, que riegan la vega de Almuñécar ${ }^{6}$ (BENAVENTE HERRERA, 1985: 140).

Hay que notar que en todas estas zonas, estos sistemas son conocidos con el nombre de "cimbras», denominación que quizás habrá que retener para designar los sistemas andaluces, tanto por su carácter generalizado como por su aparición en los documentos de finales del s. XV y s. XVI 7 .

Podemos recordar muy rápidamente su principio de funcionamiento. Se trata de largas galerías de captación, practicadas en el lecho seco de un río o de una rambla, que permiten drenar la capa de aguas subálveas subyacente cuando esta se sitúa a poca profundidad. La pendiente de la galería, inferior a la del lecho del río, permite alcanzar las aguas subálveas y evacuarlas por gravedad.

A diferencia de los qanats, se trata de galerías íntegramente construidas, en general en una sola vez, encajadas en zanjas practicadas en los aluviones muy poco cohesionados. Su trazado no es paralelo a las orillas sino que atraviesa el lecho oblicuamente de una orilla a otra presentando así una mayor superficie de captación (Fig. 15). Algunos ejemplares aumentan su caudal con una doble alimentación en la confluencia de una rambla (Acequias del valle de Alhama y de El Chiribayle en Guadix). Tampoco presentan «pozo madre».

Sin embargo, algunos raros ejemplares pueden comportar una cisterna de recepción circular o cuadrangular construida en la cabeza del sistema y generalmente cubierta con una bóveda. Este es el caso de la tajea de la Rambla de Aldeire en Guadix que presentaba una cisterna cuadrangular abovedada, de unos $20 \mathrm{~m}$ de larga, situada perpendicularmente a la rambla (Fig. 16) ${ }^{8}$, o de las curiosísimas cimbras de la Primera Fuente de Alhadra (Fuente Redonda) y de la Fuente de El Alquián que alimentaban la ciudad de Almería y su territorio?.

Dejando aparte estas escasas excepciones que necesitarían un estudio en mayor profundidad, la construcción de una tajea, desde un estricto punto de vista técnico, es una operación relativamente simple, próxima, de hecho, a la excavación de una mina o al acondicionamiento de una fuente. No exige, como en el caso de los qanats, determinar previamente la profundidad de la capa freática, ni un cálculo complejo de nivelación. A partir de la observación de la proximidad de la surgencia en el lecho del río (afloramiento temporal de agua en invierno, presencia de vegetación higrófila, existencia de otras tajeas), la zanja se practica de abajo hacia arriba hasta alcanzar la capa de aguas subálveas y obtener un caudal continuo. La empresa no es siempre coronada con éxito,

6. Estas acequias dotadas con varios acueductos son de origen romano.

7. Idénticos sistemas han sido descritos en Argelia, en el Hoggar, donde reciben el nombre de effeli, ifli, ifelen (GOBLOT, I979. pp. I43146), y en Perú en el Valle de Nazca (BARNES y FLEMING, 1995).

8. Archivo de la Comunidad de Regantes de la Acequia de Chiribayle, 1908.

9. Estos dos sistemas de captación presentaban una «taza», un ancho pozo visitable cubierto con una bóveda en cúpula y excavado en la orilla. Desgraciadamente, en la actualidad han desaparecido y es difícil saber si estos pozos, excavados en los aluviones y que drenaban las aguas subálveas, estaban alimentados por una galería o servían de sistema de captación. Según una descripción del s. $\mathrm{XIX}$, la «taza» de la Fuente Redonda se presentaba como un ancho pozo circular, de $5 \mathrm{~m}$ de diámetro y una decena de metros de profundidad, cubierto con una bóveda en cúpula, prolongado con una galería construida y guarnecida con 18 pozos de aireación (GÓMEZ CRUZ, 1986). La Fuente de El Alquian, destruida no hace mucho, presentaba una tipología similar y una escalera que permitía alcanzar la cisterna de la «taza». La segunda Fuente de Alhadra, denomina La Larga era, por el contrario, una cimbra clásica dotada con 7 pozos de aireación. 
como lo prueba la documentación subactual o los vestigios abandonados de antiguas zanjas: la capa subálvea se revela a veces demasiado profunda para que la técnica sea aplicable o simplemente rentable para sus promotores.

A medida que avanza la zanja, primero con perfil en $V$, después ensanchada en terrazas, el volumen de escombros y el coste de los trabajos aumenta de forma exponencial (Fig. 17 y 18). Una vez alcanzada el agua, la parte baja de la zanja se reviste con muretes de piedra seca, de 40 a $60 \mathrm{~cm}$. de espesor, a través de los cuales el agua se infiltra por gravedad y es encaminada por el canal de base. Según los casos, las galerías reciben una cubierta de lajas de pizarra o una bóveda de cantos calcáreos, y se recubren seguidamente con los escombros de la excavación.

Contrariamente a las cimbras documentadas en el Valle del Andarax, se trata de galerías visitables, con alturas de 1,20 m a 1,70 m y anchuras de $70 \mathrm{~cm}$. a $1 \mathrm{~m}$., que permiten el paso de una persona y al menos la limpieza parcial desde el interior de las raíces y sedimentos que reducen su caudal y terminan por colmatarlas.

La profundidad de la extremidad de la galería drenante puede alcanzar, según los casos, de 3 a 10 m bajo el nivel actual del río. Esta parte del sistema no comporta pozo de visita: estos serian inmediatamente arrancados o recubiertos y colmatados por las violentas avenidas de estos ríos y ramblas ${ }^{10}$. Las tajeas salen bajo las orillas a profundidades de 2 a 5 $\mathrm{m}$, protegidas en la mayor parte de los casos por un talud o un muro oblicuo de defensa contra las arrolladas provocadas por las tormentas. Están prolongadas con una galería subterránea de conducción, en general obrada y abovedada, dotada de dos a una decena de pozos de aireación y visita, antes de desembocar al aire libre.
La mayor parte de ellas están acopladas a presas temporales o boqueras, constituidas por una zanja superficial rodeada por tierra y ramas, que permiten recuperar una parte de las aguas de invierno y primavera, o las provenientes de las tormentas. Estas presas someras están conectadas al sistema por conductos subterráneos que desembocan en los pozos de aireación situados en las orillas. Este acoplamiento, a menudo de origen subactual, se encuentra la mayor parte del tiempo en desuso: mezcla las aguas claras y en general potables de la tajea con las aguas embarradas y cargadas de sedimentos que obstruyen el sistema de captación y colmatan la acequia, obligando a costosas limpiezas (Fig. 19 y 20). Otras galerías, como la de la Acequia de la Ciudad que alimenta los huertos y la ciudad de Guadix, no presentan presa asociada ni pozos de visita.

Las tajeas de Guadix son obras considerables, de 200 a 600 m de largo como media y hasta I Km. en el caso particular de la Acequia de El Chiribayle. Cada una de ellas asegura en verano, o más exactamente aseguraba, un caudal muy importante, si bien variable según los años y las estaciones, de 20 a 60 litros por segundo con las menos productivas y de 100 a 200 litros/s con las principales tajeas del Río de Guadix".

\section{Cronología de las redes de acequias y sistemas de captación}

Desde un punto de vista histórico, la investigación en cuanto al origen de este tipo de captaciones no está sino en sus inicios, y por el momento tan solo permite aportar algunos resultados parciales e hipótesis de trabajo.

En numerosas regiones, la profundidad de las capas freáticas y la ausencia de surgencias naturales permiten, sin muchos problemas, asociar el sistema de captación por qanat a su red de

10. No obstante, algunos raros ejemplares presentan pozos a los largo de su recorrido, como la tajea de El Algarabejo situada en una pequeña rambla poco expuesta a las avenidas.

I I. Hidrogramas de las resurgencias artificiales (CASTILLO PÉREZ et alii, 1986a: p. 255); Estatutos y documentación de las Comunidades de Regantes de las acequias de Chiribayle, La Ciudad, La Torre, Baja, Jurel, Rama, Ranas, Lupe, Rapales y Fuentes Altas y Bajas. 
distribución y al poblamiento antiguo con el que estaba relacionado. Por el contrario, en la región de Guadix la variedad de recursos hídricos, la complejidad y la imbricación de los sistemas, el carácter superficial y el nivel muy variable de las aguas subálveas, invitan a una gran prudencia a la hora de identificar los sistemas de captación antiguos correspondientes a cada red.

Como muestra el estudio de Los Repartimientos y diversos documentos de finales del $\mathrm{s}$. $X V$, las redes de acequias de la Vega de Guadix ya están todas establecidas en el momento de la conquista cristiana, prácticamente tal como podemos observarlas hoy día. Sin embargo, en principio, nada nos permite afirmar que todas estas acequias, o incluso solo algunas de ellas, estaban alimentadas por tajeas, como lo están hoy día.

Si damos crédito a lo que nos dice un autor como Al-Idrīsī, hacia mediados del s. XII, «la région de Guadix est abondamment pourvue en eau, grâce à une rivière qui ne tarit jamais») (AlIDRĪST̄, 1866). Ahora bien, esta locución podría ser exacto reflejo de la realidad o bien tratarse de una simple fórmula literaria, o de una indicación susceptible de otra interpretación, tal como encontramos en el caso de la descripción que nos da en el s. XVII Henriquez de Jorquera a propósito del río totalmente seco de Almería: "(...) pasa por medio de la ciudad, si bien por debajo de tierra, un copioso rio que se hunde antes de su entrada, que es cosa de gran maravilla..." (HENRIQUEZ DE JORQUERA, 1987: p. 100).

Sin embargo, en la región de Guadix, mucho más rica en agua, numerosas variables pudieron contribuir a la desaparición total de las aguas superficiales del Río de Guadix a principios de la primavera, tal como lo podemos observar en la actualidad.

Si bien es difícil de estimar, se debe tener en cuenta en primer lugar la probable influencia de las variaciones de las condiciones climáticas. Como en todo el sudeste andaluz, esta comarca experimenta un grave proceso de desertificación, de erosión y de colmatado, principalmente de origen antrópico ${ }^{12}$. En época medieval, y más particularmente a lo largo del altomedievo, la mayor parte de la Hoya de Guadix y de las montañas que la rodean presentaban una densa cubierta forestal de encinas, pinos, olmos y robles, cada vez más degradada en el curso del periodo moderno, hasta su total desaparición hacia finales del s. XIX y principios del $X X$. Esta masiva deforestación, la aceleración de la erosión y la importante colmatación de la red hídrica, probablemente más agravada con la implantación de numerosos sistemas de regadío, pudieron contribuir ampliamente en el cambio de régimen de los cursos de agua y en la desaparición de las surgencias.

Las necesidades de agua, con toda evidencia, no han cesado de aumentar a lo largo del tiempo, se trate para abastecimiento de la ciudad y de las aglomeraciones rurales, de las tierras en regadío, o de las nececesidades artesanales e industriales (tenerías, baños, molinos, batanes, herrerías hidráulicas, fabricas de azúcar del s. $\mathrm{XIX}$, etc.). Respecto de lo agrícola, la gestión del agua de numerosas redes ha sido igualmente modificada en función de los sistemas de propiedad y de los tipos de cultivos, de autoabastecimiento o especulativos. Los sistemas de reparto y regulación (imposición y rotación de cultivos, barbechos, cultivos de invierno y de primavera, etc.), cuidadosamente reglamentados en época musulmana, fueron particularmente trastocados a partir de la conquista cristiana. Estas importantes modificaciones en la gestión del agua pueden implicar un aumento del caudal necesario que varía de simple a doble para una misma acequia, sin que ello implique una extensión de la red y de las tierras cultivadas.

A medida que aumentaban las necesidades, las captaciones no cesaron de multiplicarse. El origen y las diferentes etapas de implantación de las múltiples redes de regadío en esta región están lejos de ser conocidos a día de hoy, pudiendo reservar algunas sorpresas.

12. Sobre este mismo fenómeno para la vertiente sur de Sierra Nevada, ver: CASTILLO REQUENA, 1996. 
Una investigación, publicada recientemente, nos da la escala posible de los problemas de cronología, con la datación de dos canales de acequias de travertino (stone-snakes), alimentados por las fuentes termales de Alicun. Los análisis AMS Radio Carbono, realizados a partir de concentrados de pólenes, han ofrecido fechas de $3360 \pm 40 \mathrm{BP}$ et $2660 \pm 60 \mathrm{BP}$, correspondientes al Bronce final y a principios del periodo ibérico (DÍAZ HERNÁNDEZ et alii, 2000).

Pocos son los datos disponibles por el momento sobre el regadío en época romana. La precoz colonización de las tierras de montaña, con sus minas de cobre y plata equipadas de galerías de achicamiento, y el establecimiento de la colonia romana Julia Gemella Acci, centrada en el emplazamiento de Guadix, una antigua instalación ibérica, se vieron acompañadas muy probablemente de la instalación de nuevos sistemas hidráulicos. En medio rural, un gran número de granjas y villas romanas estaban alimentadas por fuentes cuidadosamente canalizadas: canal de la acequia de la villa de Paulenca (SANTERO SATURNINO, 1975), acequias de las villas de Fuente Álamo, Jolopos y Graena, canalizaciones de la villa de Cauzón, etc. (BERTRAND y SÁNCHEZ VICIANA, 2006). Por su parte, la ciudad de Guadix disponía de varias fuentes, visiblemente ya acondicionadas en esta época, tal como parecen indicar los vestigios de opus signinum que recubren ciertas partes de las canalizaciones.

Sean cuales fueren los antecedentes, el más intenso periodo de instalación de nuevas redes, y más particularmente de redes de regadío, se sitúa, como en todas partes, en el curso del periodo islámico, evidenciado en esta región por una serie de documentos cuya cronología se extiende desde principios del s. XIl hasta el XV. Prácticamente todos estos textos, producto de pleitos, hacen estado de la captación y desvío en cabecera de las aguas de los torrentes de montaña, para poner en cultivo los piedemonte y la altiplanicie o para la alimentación de la ciudad, en detrimento de las tierras bajas. Tal es el caso de la Acequia de La Sierra, de las de Bertillana, Lugros y Albuñán (GONZÁLEZZ PALENCIA, 1940) o de la Acequia de Cogollos ${ }^{13}$.

Los ss. XI y XII, que se corresponden con el periodo de Taifas y de la dominación Almorávide y Almohade, se presenta por el momento como uno de los más intensos en cuanto a la instalación de redes de regadío en esta región ${ }^{14}$.

\section{Estudios de Caso}

\section{EL VALLE DEL RÍO ALHAMA}

El Valle del Río Alhama, situado al W de Guadix, presenta los tres tipos principales de sistemas de captación presentes en la región: presas en los torrentes de montaña, minas de agua que aumentan el caudal de pequeñas surgencias, y galerías de drenaje de aguas subálveas (Fig. 21). Parecía ofrecer, en principio, la posibilidad de un estudio de caso más simple y una primera datación relativa de los sistemas de irrigación, antes de emprender el estudio más complejo de los sistemas del Valle de Guadix.

El análisis de la distribución del poblamiento en este valle parece indicar claramente que los sistemas de regadío más antiguos se situaban en el curso medio del río Alhama (BERTRAND y SÁNCHEZ VICIANA, 2006). Efectivamente, sobre sus riberas se concentran la mayor parte de los yacimientos arqueológicos desde el neolítico, las granjas y villas romanas, el hábitat disperso visigodo y emiral, y las alquerías de la Alta Edad Media. Debido a su fuerte pendiente y a

13. Manifiesto Juridico...sobre la propiedades de las aguas de Cogollos, por el Lic. D. Esteban Mauricio de Arilla, 1721, Archivo particular.

14. Una de estas etapas pudo ser protagonizada por Ahmad b. Milhan, en la primera mitad del s. XII. Según Ibn al-Jațib ('Amal), este sublevado gobernador de Guadix, rodeado con una corte de intelectuales y sabios, desarrolla la agricultura en Guadix y visiblemente el regadío. Sometido a los Almohades en I I52-53, emigra a Marrakech donde fue encargado de los trabajos de construcción y de irrigación de la Buhayra imperial (LEVI-PROVENÇAL y GARCÍA GÓMEZ, 1981: 171 n. 12 ). 
la importancia de su caudal en origen, podría haber sido un curso de agua perenne antes de que fuese implantada en cabecera la gran red de irrigación de la Acequia de la Sierra.

Este extenso sistema divide en dos y desvía la totalidad del agua procedente de Sierra Nevada que, con anterioridad a su implantación, alimentaba al Río Alhama (Fig. 12). Se trata de un verdadero transvase que dirige la mayor parte del agua hacia el territorio de la ciudad de Guadix y hacia la altiplanicie, para regar una vasta extensión de tierras, unas 1400 $\mathrm{Ha}$. El estudio realizado a partir de los textos árabes ${ }^{15}$ y de los restos arqueológicos de los poblados de nueva implantación que alimenta en la altiplanicie, ha permitido acotar su época de construcción, relativamente tardía, hacia finales del $s$ X - principios del s. XI. Cabe pensar que, a partir de estas fechas, esta importante captación pudo tener serias repercusiones en la adquisición y gestión del agua de las redes más antiguas situadas aguas abajo.

A pesar de ello, algo más abajo, en el curso medio, el agua proveniente de fuentes y surgencias permite la existencia de una red de acequias, pero al precio de una organización rigurosa de los turnos de agua. Entre las alquerías de Beas, Lares y Marchal, el lecho del río prácticamente seco hace las funciones de acequia principal, y las diversas acequias, transformadas de hecho en derivaciones secundarias o brazales, utilizan el agua por turnos, agotando así las últimas aguas superficiales.

A este nivel, el sistema se completa con un alineamiento de pequeñas minas de agua, de muy débil caudal, excavadas en los barrancos adyacentes y acopladas a balsas. Estas tienen como función regar pequeñas parcelas y sus excedentes, a menudo, son recogidos por las acequias principales. Estas minas de agua, visiblemente antiguas, aparecen en la documentación del s. XVI bajo el nombre de fuente, mina o minilla. La toponimia es, según los casos, árabe (Handac al-mi, Muñana, Zamar, Xoraique, Aljofar) o latina (Funtucula, Culum, Bargana) ${ }^{16}$. Desde un punto de vista arqueológico, prácticamente todas están asociadas a vestigios de pequeñas granjas romanas y a hábitats aislados del periodo visigodo.

Las poblaciones de Purullena y Bejarín, situadas aguas abajo, no entran en esa organización de turnos de agua. Disponen de cuatro acequias de importante caudal, alimentadas aún hoy día por tajeas (Acequias del Lugar, de Humaya, del Molino, Baja y Rama) 17. Estas galerías drenantes, abovedadas con piedras calizas, han sido objeto de importantes refacciones tras la gran riada de 1973. Dos de ellas, la de El Lugar y la Acequia Baja, presentan una doble captación: una segunda tajea, practicada en una rambla adyacente, desemboca en el interior de la galería de la tajea principal ${ }^{18}$.

Estas acequias ya existían en época islámica y son identificables con las acequias de Caules/ del Molino de Umaya, Fuente del Hoyo, Colayras y Rahama, mencionadas en los libros de Repartimiento y en los de Apeo. Funcionan simultáneamente y no establecen turnos de agua entre ellas, a diferencia de las acequias situadas aguas arriba. Durante el s. XVI permiten el riego de unas $200 \mathrm{Ha}$, la misma extensión de tierras de huerta de hoy día, y mueven tres molinos. Cabe notar que al menos dos de estos molinos, mencionados en |49|, son netamente prioritarios en la utilización de las aguas de sus respectivas acequias, Molino de Umeya y Molino de Rahama, ya en ruinas en esta época y que da su nombre a la acequia (del ar. Rahā : molino) ${ }^{19}$.

\footnotetext{
15. El primer documento conservado relativo a esta acequia data de II39 (Archivo de la Catedral de Guadix); Archivo de la Real Chancillería de Granada, Pleito sobre aguas, 3a-325-3; (MOLINA LÓPEZ, 1991); (ESPINAR MORENO, 1987a y 1987b).

16. Archivo de la Real Chancillería de Granada, Apeos de Loaysa: Beas: 5-al-26; Marchal: 5-a3-108; Purullena: 5-a4-|41.

17. El nivel piezométrico en este sector se sitúa en 1988 entre 3 y 7 m (GONZÁLEZ TAPIA, 1988).

18. Planimetrías de la Acequia Baja y de la Acequia de Humeya, Y.R.I.D.A; Estatutos y Reglamento de la Acequia Baja.

19. Archivo Municipal de Guadix., Libros de Repartimiento, T. I, Merced de Fernando de Ysla.
} 
Las redes de regadío de la Acequia de La Sierra y las del curso medio e inferior del Alhama están plenamente instaladas a finales del s. XV. Los volúmenes de agua necesarios para el funcionamiento de las acequias situadas totalmente al final del sistema y la presencia de molinos árabes, parece implicar, a priori, la existencia de sistemas de alimentación por tajeas con anterioridad a la conquista cristiana. Los datos arqueológicos recogidos por el momento sobre estas dos poblaciones de Purullena y Bejarín que dependían de sus acequias (material cerámico, tipología del hábitat troglodita medieval y morisco), parecen indicar claramente que se trata de nuevas fundaciones del periodo nazarí (ss. XIII - XV) (BERTRAND, 1993).

\section{LA VEGA DE GUADIX}

En la vega de Guadix nos encontramos en presencia de un sistema más complejo, a pesar de presentar grandes similitudes con el escalonamiento de sistemas de regadío del Río Alhama (Fig. 22 - 23).

En el piedemonte y en el llano encontramos las grandes acequias que nacen en Sierra Nevada y que captan en cabecera la totalidad de las aguas superficiales, (Acequias de Jerez, Cogollos, Albuñán, Guadix, etc.) (Fig. 12). En base al estudio arqueológico y documental, un buen número de estas acequias habrían sido implantadas a lo largo de los periodos almorávide y almohade (BERTRAND y SÁNCHEZ VICIANA, 2006). Estos sistemas, que restituían las aguas excedentarias a la red hidrográfica del Río Verde, fueron prolongados repetidas veces para regar el llano en el curso del periodo nazarí y más particularmente a lo largo del periodo moderno, utilizando así prácticamente todas las aguas superficiales disponibles. La superficie regada actualmente es de II.000 Ha (I800 $\mathrm{Ha}$ en regadío fijo y $9.200 \mathrm{Ha}$ en regadío eventual).

La enorme masa de sedimentos en el curso medio del Río Verde no permite, como en el caso del Río Alhama, la existencia de un sistema de irrigación intermediario. Las aguas subálveas han podido resurgir de forma natural en la zona de Alcudia, en la cabecera de la vega de Guadix, tal como parece mostrar la importante fuente que alimenta esta población, o las captaciones ocasionales mediante simples zanjas, a veces realizadas por los agricultores de Alcudia en el lecho del río con anterioridad a la drástica bajada del nivel freático ocasionada por los trabajos de la mina de hierro de Alquife.

Con anterioridad a estas fechas, las 24 acequias principales que se sacan del Río Verde, - Río de Guadix, y que riegan una huerta de unas $1.500 \mathrm{Ha}$, estaban tan solo alimentadas por tajeas.

Como muestran por ejemplo las 3 tajeas de la Acequia de Jurel, o las 4 galerías de la Acequia de Ranas, prácticamente cada acequia presentaba varias alimentaciones por galerías drenantes, instaladas en el mismo lecho del río, o injertándose a lo largo del camino a partir de ramblas afluentes (Fig. 24).

Se ha emprendido un estudio regresivo de estas redes a partir de los sistemas que todavía funcionan y de las diversas Ordenanzas y documentación de los archivos de las Comunidades de Regantes de cada una de estas acequias. Estos archivos están muy desigualmente conservados, a menudo irremediablemente perdidos. Algunos, sin embargo, como el de la Acequia del Chiribayle o el de la Acequia de la Ciudad, que permiten remontarse al último cuarto del s. XIX y a veces más atrás, ofrecen preciosas informaciones sobre los sistemas de captación, designados corrientemente en los informes oficiales bajo el nombre de atarjeas o tajeas, y más raramente como canalillos.

Los documentos que abarcan desde los años 70 del s. $X I X$ hasta los años 40 del s. $X X$ evidencian una incesante actividad de reparación de tajeas antiguas, de hallazgo y reconstrucción de algunas de ellas, pero también de excavación de nuevas galerías de captación. Por el contrario, otras consideradas irrecuperables son abandonadas. Para dar un ejemplo, la Acequia de Chiribayle dispone de dos tajeas en |89|, cinco en 1915, tan solo comporta dos en 1929, y solamente una está todavía en funcionamiento en la actualidad. 
Los proyectos, los planos de ejecución, los presupuestos y las notas de gastos, traducen claramente la importancia de los trabajos que implican la construcción de estos dispositivos y sus gastos constantes de mantenimiento. Con una frecuencia significativa, las avenidas y el desbordamiento de las ramblas dañan gravemente, destruyen o entierran las galerías drenantes bajo enormes masas de aluviones ${ }^{20}$. La red hidrográfica, enmarcada por taludes y muros de defensa, no cesa de sobreelevarse respecto de las tierras irrigadas, favoreciendo su inundación periódica. Las tajeas que presentan un canal de conducción profundamente enterrado bajo las riberas y las tierras de cultivo, como las de la Acequia de la Ciudad o la Acequia de Almecín, son probablemente los dispositivos más antiguos que se han conservado ${ }^{2 !}$. La importancia de este fenómeno de colmatación está por estudiar para los periodos históricos y varía probablemente según los sectores. Al pie de la ciudad de Guadix, el nivel del Río Verde ha subido más de un metro en el curso de estos últimos diez años. En 1996, con ocasión de una excavación de urgencia, desgraciadamente aún no publicada, practicada cerca de la orilla, han podido ser observados los restos de un arrabal del periodo almohade, cubiertos con unos 2,50 $\mathrm{m}$ de sedimentos procedentes de sucesivas inundaciones.

Si juzgamos a partir de la documentación de la Acequia de Chiribayle, una sola reparación de tajea descubriéndola necesita 500 jornadas de trabajo de terraplenadores, repartidas en dos meses y medio, de 15 a 30 peones, 3 albañiles y I maestro de obra, un millar de adobes, 50 quintales de cal y varias toneladas de piedra calcárea que es necesario extraer y transportar desde el llano. A menudo se considera más rentable excavar una nueva galería a pesar de los problemas de nivelación que plantea el acoplamiento a la red de riego existente. Estas dificultades de conexión, los acuerdos estable- cidos con los propietarios de los terrenos y entre las diferentes Comunidades de Regantes están probablemente en el origen de diversas anomalías constatables en la alimentación de ciertas redes (puesta en comunicación de acequias que en su origen disponían de una galería de captación independiente, desembocadura de la galería drenante sobre la orilla opuesta y engarce por sifón, como en el caso de la Acequia de Jurel).

Dado el coste de los trabajos, habitualmente los promotores de nuevas tajeas son ricos terratenientes, propietarios de molinos, a veces la ciudad de Guadix, y sobre todo en este momento las dos fabricas de azúcar que se instalan en Guadix y Benalúa en 1901. Estas, para satisfacer sus importantes necesidades en agua, encargan la excavación de las tajeas a la Sociedad Moran, una empresa especializada en trabajos hidráulicos establecida en Madrid.

El propietario del terreno es igualmente propietario de las aguas si es él quien realiza los trabajos. Pero en todos los casos, acuerdos de compra de terreno, de arrendamiento o de toma en carga de los trabajos son establecidos por las Sociedades de Regantes para ligar estas tajeas al sistema comunitario de regadío, explicando así la multiplicidad de galerías de captación que a menudo alimentan una misma red.

\section{LOS PROBLEMAS DE DATACIÓN. PRIME- ROS DATOS CRONOLÓGICOS}

Tal como muestra la documentación de finales del s. XV, las 24 acequias principales que irrigan las tierras de Alcudia, Esfiliana, Guadix, Bejarín y Benalúa funcionan simultáneamente en ese periodo, sin mantener turnos de agua entre ellas. En I57I riegan más de $1.300 \mathrm{Ha}$ de alamedas, huertas, vega y viñas, y accionan un gran número de molinos, la mayor parte de dos piedras lo que permite una actividad

20. Las ramblas de Aldeire y de Baza, y sobre todo la extensa rambla no dominada de Fiñana, que amenaza la misma ciudad de Guadix, son sin duda las más destructoras. En el curso de los últimos 30 años se han producido dos riadas catastróficas, en 1963 y 1973, y otras cuatro de menor amplitud en 1969, 71,79 y 91 (DELGADO, 1996).

21. La galería de la tajea de la Acequia de Almecín desemboca bajo la orilla a unos 6 m de profundidad. 
continua ${ }^{22}$. Cabe preguntarse cómo, en ausencia de galerías drenantes, el lecho del Río de Guadix, en la actualidad totalmente seco durante 9 ó 10 meses al año, habría podido abastecer en esa época los 30 a $40 \mathrm{Hm}^{3}$ por año necesarios para la alimentación del sistema. No obstante, la existencia de estas galerías queda por probar.

La prosecución del estudio regresivo en esta región no será fácil de realizar. La documentación del tribunal de aguas, que remontaba a principios del s. XVI, se quemó en la Guerra Civil. En el resto de archivos en los que es posible trabajar actualmente ${ }^{23}$, las tajeas no aparecen en los textos no especializados, siendo designadas como simples fuentes, igual que en la toponimia local: Fuente de Benajara, Fuente de Cuerva, o incluso Fuente de La Tajea, por dar algunos ejemplos ${ }^{24}$.

En los textos topamos con las mismas dificultades que las encontradas en el estudio etnográfico: "...el agua se saca del rio, nace en el rio...". Cuando se identifica la posición de estas "fuentes" que alimentan las diferentes acequias, efectivamente todas se suceden unas a otras a poca distancia en el lecho del río, inmediatamente sobre sus riberas o en el lecho de una rambla, probando con toda evidencia que la red hidrográfica no tiene un carácter perenne. Aun si existían de forma natural, la utilización para el regadío de estas surgencias en estas amplias ramblas implicaría su acondicionamiento y su canalización, aunque fuera a través de simples zanjas.
El carácter privado de una buena parte de estas tajeas, y a menudo de las redes de regadío que alimentan, en manos de grandes terratenientes y de propietarios de molinos es particularmente evidente a lo largo del periodo moderno, detectable a través de la toponimia (Fuente de Vílchez, Fuentes del Tío Colorín, de Feliciano, de Vergara, etc.) o evidenciada por los textos (tajeas privadas de los molinos de Peñuela, del Cabo de la Banda, de Don Alfonso Labella...). Tal es el caso de las captaciones y acequias de Benalúa y de Xeque (Palomar), propiedad particular del Duque de Gor, del Marques de Villalegre y de la Condesa de Alcudia ${ }^{25}$ o, en el siglo XVI, de la Fuente de Aute que alimentaba a la acequia de la población de Alcudia. Según el apeo de I57I, los habitantes de esta población habrían comprado esta "fuente", hacía ya tiempo, por 4 arrobas de seda a un morisco llamado Umayya ${ }^{26 .}$

El término de tajea o atarjea, utilizado en los documentos de las Comunidades de Regantes, no ha sido encontrado en la documentación más generalista anterior al s. XIX que ha podido ser consultada hasta el momento. En cualquier caso, otra terminología podría haber sido empleada para designar estas obras. Dos galerías drenantes, hoy día desaparecidas, situadas en dos ramblas afluentes del Río Alhama, están mencionadas claramente en un texto de |57|, igual que en la Región de Almería, con el término de zimbra: Zimbra de Carboneras y Zimbra de Algoroz 27.

Igualmente, éste podría ser el caso de los vocablos "pontana" y "pontanilla", que designan

22. Archivo de la Real Chancillería de Granada, Apeo del Marquesado del Cenete y de sus villas, 2I6-D6.

23. La mayoría de los archivos de la provincia de Granada están actualmente cerrados, algunos desde varios años, por obras o por falta de financiación (Archivo de la Real Chancillería, Archivo Histórico Provincial, Archivo Municipal de Granada, Archivo Notarial de Guadix, Archivo Municipal de Baza). Otros, teóricamente públicos, como el de La Confederación Hidrográfica del Guadalquivir, de hecho no autorizan ninguna consulta.

24. Sin pretender una lista exhaustiva, se puede citar la Fuente del Hoyo, la Fuente de los Guindos, la Fuente Baja en el Valle de Alhama. Para el Río de Guadix: Fuente de Aute, Fuente Tejada, Fuente de la Reja, Fuente de Albuñan, Fuente de la Higuera, Fuente de Jurel, Fuente Chica, Fuente de Rompicazo, Fuentes de la Bonilla, de las Negras, del Rután, de la Ciudad. Fuente de Santa Teresa para el Río de Aldeire. Fuente de los Enamorados, de las Natias, del Caracol, de las Viñas, Galindo para el Río Nacimiento.

25. Archivo Histórico de la Diputación Provincial de Granada. Contencioso entre el Ayuntamiento de Benalúa y el Duque de Gor (...), I848, Leg. 2633, Pieza 002; (SÁNCHEZ GÓMEZ, 2000: pp. 139-142).

26. Apeo de Alcudia y Esfiliana, A.R.C.Gr., 5-a4-I4I; Archivo Municipal del Valle del Zalabí.

27. Apeo de Beas, Archivo de la Real Chancillería de Granada, 5-al-26. 
una galería cubierta de lajas y que, por su contexto, también parecen denominar una tajea. El término zanja que, como hemos visto, hace referencia a una fosa en general no cubierta para extraer y canalizar el agua subálvea situada a poca profundidad, también hace parte del vocabulario popular actual. Aparece en los informes de los ingenieros del s. XIX, pero también en el s. XVI en los Libros de Apeo de Esfiliana y Alcudia.

Desde un punto de vista arqueológico tampoco será fácil encontrar y datar las eventuales tajeas medievales, dadas las continuas refacciones y reconstrucciones de las que han sido objeto, sus desplazamientos y el importante proceso de colmatación de la red hidrográfica. No obstante, varias tajeas antiguas han sido encontradas enterradas bajo varios metros de sedimentos con ocasión de trabajos de acondicionamiento del Río de Guadix, como es el caso de la tajea de la Acequia de Rapales, hoy día desprovista de alimentación propia y ligada con un sifón a la Acequia de Ranas. Otra galería abandonada, construida con grandes ladrillos y mortero de cal, que ha sido localizada en la orilla izquierda del Río de Guadix, cerca del molino de Los Guindos, podría corresponder a una antigua captación de la Acequia de Bejarín (Fig. 25). Otras dos han sido exhumadas, una en la rambla de Fiñana, en piedra seca y provista de pozos (Fig. 26), y otra que alimentaba el aljibe de la población de Purullena en época morisca. Los trabajos de encauzamiento previstos próximamente en el lecho del Río de Guadix quizás permitirán avanzar en esta vía.

El estudio del poblamiento antiguo asociado a cada acequia y el análisis de los textos comienzan a ofrecer algunos elementos de cronología para ciertas redes. Como vimos en el caso del Río Alhama, hay muchas probabilidades de que las acequias situadas al final del sistema, por su posición, sean las más recientes y hayan comportado tajeas. Las cuatro últimas, de Quinte, de Abenjalin (Bejarín), Benalúa y
Xeque (Palomar), situadas aguas abajo de la ciudad, estaban asociadas cada una de ellas a una pequeña alquería medieval del mismo nombre, formadas por hábitats troglodíticos reagrupados alrededor de una torre. La tipología de las cuevas y la del material cerámico asociado indican que se trata de nuevas implantaciones de los ss. XIII - XV. Estas pequeñas aglomeraciones y sus territorios parecen pertenecer a jefes de linaje $\mathrm{o}$ a altos funcionarios, ligados a la antigua "nobleza" nazarí de Granada o de Guadix. Algunos de ellos, convertidos en colaboracionistas, conservan sus propiedades en esta zona tras la conquista cristiana.

Este es el caso de Abraham Aben Aceyte, antiguo secretario del Zagal, y de su linaje, que poseía la torre y alquería de Xeque, al menos desde el s. XIV 28. En el caso de Benalúa, la mayor parte de las tierras pertenecían a Cetimaleoli, viuda de Alhaje Aben Aceyte, caudillo de Guadix, y esposa de Ali Aduladin, miembro de otra importante familia nazarí ${ }^{29}$. También este es el caso de Ali Abenajara, tesorero de las rentas reales en época nazarí, quien visiblemente da su nombre a la "Fuente de Benajara" de la acequia de Bejarín.

La propiedad privada de ciertas aguas e incluso de sistemas de irrigación es, como se sabe, una situación relativamente corriente en época nazarí, y a fortiori si efectivamente las aguas provienen de galerías drenantes, sistemas que necesitan una fuerte inversión, se trate de su construcción o de su mantenimiento. Según al-Māwardī y otros diversos juristas, las aguas ocultas cuyo alumbramiento ha sido provocado por el hombre se convierten en propiedad de aquel que las ha hecho surgir. Si el fundador de la fuente es propietario del terreno, tiene un derecho superior para emplearlas en regar una tierra muerta. Si hay excedentes, debe hacer donación a aquel que tenga necesidad para beber y a los propietarios de ganado, no a los agricultores a quienes puede reclamar una contrapartida (LAGARDĖRE, 1988-89).

28. Crónica de Santa Maria, CODOIN, vol. C, pp.367-368; Archivo Municipal de Guadix. Libros de Repartimiento, Leg. 2, merced n 81. 29. Archivo Municipal de Guadix., Libros de Repartimiento, Leg. I, Merced n 4 I. 
Las aguas que alimentaban la ciudad de Guadix y su territorio inmediato disfrutaban, probablemente, de otro estatuto, pero nada por el momento, en la poca documentación actualmente disponible, nos permite remontar más alto en el tiempo. No obstante, podemos tomar como posible paralelo el sistema de alimentación en agua de la ciudad de Almería, procedente de las "Fuentes" de Alhadra y documentadas desde principios del s. Xl.

A diferencia de lo visto para Guadix, la captación de aguas subálveas mediante tajeas, o cimbras como aparecen en la documentación de la conquista cristiana, constituían el único modo posible de alimentación de la ciudad ${ }^{30}$. Estas galerías, que pertenecían a la Mezquita Mayor de Almería, fueron atribuidas consecuentemente a los bienes habices de la Catedral, ocasionando desde principios del $\mathrm{s}$. $\mathrm{XVI}$ un largo proceso con la ciudad (SEGURA DEL PINO, 1995). Según los testigos moriscos citados con ocasión de este litigio, la primera "Fuente" de Alhadra habría sido construida a su cargo, hacía ya un buen momento, por un personaje nombrado según las diversas transcripciones Aherin, Haerin y Jaerin, identificable con Jayrān ( I 0 | 4- | 028), citado por Al-Himyarī y Ibn al-Jațiib ${ }^{31}$. Este personaje hace donación de una parte de las aguas a los habitantes de la ciudad para beber, y habría pasado la otra parte a los bienes habices de la Mezquita Mayor. Los cadíes y alfaquíes procedían, cada viernes, a la venta pública de este agua para la reparación de la muralla de la ciudad. La segunda "fuente" (probablemente La Larga) habría sido alumbrada, poco tiempo después, por otro personaje llamado Jasaf o Jahab, siendo objeto de un acuerdo con Jayrān: una parte de las aguas era destinada a llenar los aljibes, otra a la reparación de las muralla y la tercera parte, que quedó propiedad de Jasaf, fue vendida a los propietarios de tierras para regadío (SEGURA DEL PINO, 1995). La tercera cimbra, la de El Alquian, sin duda de origen más reciente, era propiedad privada a principios del s. XVI y sus aguas eran repartidas entre diversos propietarios (MARTíNEZ SAN PEDRO, 1989).

Como en el caso de Almería, las ciudades y las grandes aglomeraciones rurales, que necesitaban importantes cantidades de agua clara o potable, han sido probablemente las primeras en beneficiarse de estos sistemas.

\section{SITUACIÓN ACTUAL}

Hoy nos queda poco tiempo en Andalucía Oriental para estudiar estos sistemas que corren el riesgo de desaparecer completamente en algunos años. Las antiguas captaciones de la ciudad de Almería están hoy día destruidas o profundamente enterradas, y tan solo menos de una decena de tajeas (Chiribayle, Ciudad, las del Río Alhama, Cigüeñi, Albuñán), todas ellas acopladas a pozos, están aun en funcionamiento en la región de Guadix.

Como en todas partes, para la aducción de agua corriente a la ciudad y a las diferentes poblaciones, para aumentar el caudal de las acequias o, en buena parte de los casos, para escapar a las servidumbres comunitarias de la Comunidades de Regantes, desde los años 50 han sido perforados numerosos pozos en las

\footnotetext{
30. Estos sistemas, regularmente arramblados o dañados por las fuertes avenidas del río de Almería, han sido restaurados, reconstruidos y visiblemente modificados o desplazados en numerosas ocasiones a lo largo del periodo moderno (LÓPEZ ANDRÉS, I 989 ; GÓMEZ CRUZ, 1989; ANDUJAR CASTILLO, 1989). Según las indicaciones de los textos más antiguos, La Fuente Larga, que nace en el mismo lecho del río y presenta un muy pequeño número de pozos en la orilla, parece claro que se corresponde con una tajea normal. La topología de la Fuente Redonda y de la Fuente de El Alquian, provistas de una "taza" en el s. XIX, plantean otro problema. La bóveda de la "taza" de la Fuente Redonda existía al menos en 1618 y ya había sido restaurada en esa fecha tras una fuerte riada ; su profundidad era sin duda menos importante : en $|73|$, el sistema comportaba tan solo 6 pozos (I8 en el $x$. XIX). En cuanto a La Fuente de El Alquian, presentaba otro trazado y posiblemente una tipología diferente con anterioridad a 1618:"antiguamente yba el agua de dicha fuente por otra cimbra y no por la que oy va y que el camino que antiguamente yba simbra biexa echa por debajo de tierra..." (ANDUJAR CASTILLO, 1989).

31. “Este príncipe (Hairān el Amirita) llevó a este barrio (de al-Musallā) agua de una fuente vecina por medio de una canalización. Muhamad Ibn Sumādih continuó después esta canalización hasta la mezquita mayor de Almería, en el interior de la ciudad propiamente dicha y la abasteció con la misma agua" (Al-Himyarī, 1963, 367).
} 
proximidades de las tajeas lo que ha contribuido a desecar numerosos sistemas ${ }^{32}$.

Como muestra claramente la propia documentación de las Comunidades de Regantes, las galerías drenantes necesitan un mantenimiento permanente, anual, se trate de la limpieza interior, de reparaciones o de reconstrucciones. Numerosas refacciones han sido realizadas en sus canales de conducción, especialmente con ocasión de la gran riada de 1973 que arrolló la mayoría de ellas. En muchos de los casos estudiados, no obstante, la galería drenante propiamente dicha, completamente enarenada, no ha sido visitada ni limpiada desde más de 30 años, o incluso desde después de la Guerra Civil, momento en el cual buen número de prisioneros y represaliados debieron realizar este trabajo.

A pesar de la importancia de los volúmenes a extraer, la utilización de estos sistemas podría haber continuado todavía durante un buen número de años, dada la importancia de la recarga del acuífero y la posibilidad de utilizar toda una serie de técnicas: maquinaria de aterrazamiento para el mantenimiento de las galerías subterráneas, riego por aspersión o goteo, control de los pozos, etc.

Sin embargo, desde los años 70-80 la explotación de hierro de la mina de Alquife, situada en cabecera del Río de Guadix, en el Ilano, eliminó esta posibilidad. El enorme cráter de la mina a cielo abierto, con una profundidad de más de 300 m, ha atravesado completamente las capas freáticas, obligando a la instalación de dispositivos de bombeo cada vez más numerosos y eficaces con el fin de permitir la explotación de las reservas de mineral inundadas. Los volúmenes de extracción de agua sobrepasaron los de recarga y conllevaron una intensa bajada de la capa freática y el secado de la practica totalidad de las tajeas del Río de Guadix y de sus ramblas afluentes (CASTILLO PÉREZ, 1986).
Fue diseñado e instalado por la Compañía Andaluza de Minas un sistema de recarga del acuífero, utilizando las aguas de bombeo en cabeza de la Rambla del Berral (DELGADO MOYA, 1986; LOISY, 1992), pero el cierre de la explotación minera y la interrupción de los bombeos en 1996 se ha saldado con la inundación de la mina y el abandono del sistema de recarga (FERNÁNDEZ MÉNDEZ, 1998). Un estudio está en curso con objeto de intentar medir la futura reacción del acuífero.

Aun con esto, la política hidráulica conducida por la Confederación Hidrográfica del Guadalquivir (grandes presas de regulación y trasvases de las aguas superficiales hacia regiones con agricultura intensiva como Sevilla, Córdoba y Almería, recarga tarifada de las acequias, etc.), apenas si parece abrir la vía a una eventual recuperación de las tajeas de la región de Guadix.

\section{BIBLIOGRAFÍA}

\section{Fuentes y Traducciones}

AL-HIMYARĪ (1963): Kitāb al-Raw d al-Mi'țār, trad. P. Maestro Ġonzález, Valencia.

AL-IDRĪSĪ ( I 866) : Description de l'Afrique et de l'Espagne par Edrisi, trad. E. Dozy, Leyde.

GONZALEZ PALENCIA, A. ( 1940): "Documentos árabes del Zenete", in Al-Andalus, 5, pp.30I-382.

HENRIQUEZ DE JORQUERA, Fr. (1987): Anales de Granada, Ed. A. Marín Ocete, Granada.

IBN AL-JATīB ( 1956) : Histoire de l'Espagne musulmane extraite du «Kitāb A'māl al-A'lām», Ed. Lévi-Provençal, Beyruth.

LEVI-PROVENÇAL, E. ; GARCIA GOMEZ, E. (198I) : EI siglo XI en la la persona. Las "memorias 》 de 'Abd Allāh ultimo rey zirí de Granada destronado por los Almorávides (1090), Madrid, Alianza.

32. Los gastos de explotación de estos pozos y los robos y costosas reparaciones de los motores de bombeo han conllevado desde entonces el abandono o la no utilización de muchos de ellos. En el curso de estos últimos años, la situación se ha agravado aun más a causa del fuerte éxodo rural y por la elevada edad de la mayoría de los agricultores que ya no cultivan sus tierras y las conservan a titulo de garantía de pensión. 


\section{Estudios}

ANDUJAR CASTILLO, F. ( 1989): “Adaptación y dominio del agua. La vega de Almería en el primer tercio del siglo XVII", El Agua en zonas áridas. Arqueología e Historia. I Coloquio de Historia y Medio Físico, Almería., pp. 1087- 1099.

BARNES, M. y FLEMING, D. (1995): "Andarax and Nazca: Two Coastal Valleys Compared", Annual Midwest Conference of Andean Archaeology and Ethnohistory, The Field Museum, Chicago, Illinois, 20 p.

BENAVENTE HERRERA, J. (1985): Las aguas subterráneas en la Costa del Sol de Granada. Granada.

BERTRAND, M. y CRESSIER, P. ( I 985): «lrrigation et aménagement du terroir dans la vallée de l'Andarax (Almería) les réseaux anciens de Ragol», Mélanges de la Casa de Velázquez, T. XXI, pp. I I5-I35.

BERTRAND, M. (1990): «Les habitats de falaise d'occupation almohade et proto-nasride dans la dépression de Guadix Baza (Province de Grenade)», La maison Hispano-musulmane. Apports de l'Archéologie, Granada, pp. 47-7I.

BERTRAND, M. (1993): L'habitat troglodyte de la région de Guadix (Andalousie Orientale). Tesis doctoral inédita Universidad Paris I-Sorbonne, 6 vols.

BERTRAND, M. y SÁNCHEZ VICIANA, J. R. (2006): "L'irrigation du territoire de Guadix. Les grandes acequias de Sierra Nevada. L'Acequia de la Sierra", La maîtrise de l'eau en al-Andalus. Paysages, pratiques et techniques, Madrid, pp. I-49.

BERTRAND, M., SÁNCHEZ VICIANA, J. R. y ZUBIAUR MARCOS, J. F. (1996): «Mines et métallurgies de la Sierra Nevada. Premières données», I Jornadas sobre Minería y Tecnología en la Edad Media Peninsular, 1995, León, pp. 180-197.

CASTILLO PÉREZ, E., DEL VALLE CARDENETE, M. y LUPIANI MORENO, E. (I 986a): "Características del acuífero de los llanos del Marquesado y Vega de Guadix. Nuevos datos sobre su balance hídrico", El Agua en Andalucía, T. II, Granada, pp.245-256.

CASTILLO PÉREZ, E., DEL VALLE CARDENETE, M. y LUPIANI MORENO, E. (1986b):"Demandas agrícolas de la Vega de Guadix. Bases para una mejor utilización de los recursos subterráneos", El Agua en Andalucía, vol. II, Granada, pp.461-470.

CASTILLO REQUENA, J. M. (1996): "La hidráulica tradicional en la Sierra Nevada Almeriense y en los valles aledaÔos. Datos para el estudio de un medio árido", I Conferencia Internacional Sierra Nevada, 20-22 Marzo 1996, Granada.

DELGADO MOYA, S., DEL VALLE CARDENETE, M. IGLESIAS LÓPEZ, A. y RUBIO CAMPOS, .. ( 1986):"Aprovechamiento de las aguas de drenaje del Marquesado. Proyecto de recarga artificial y mejora de los regadíos de Guadix", El agua en Andalucía, vol. II, Granada, pp. 277-289.

DELGADO, J.y GIRÓN, F. (1996): "Infraestructura hidráulica en la vertiente Norte de Sierra Nevada- Cuenca de río Fardes", I Conferencia Internacional Sierra Nevada, 20-22 Marzo 1996, Granada.
DÍAZ HERNÁNDEZ, J. I., MARTÍN, M. y JULIA, R. (2000): "Depósitos travertínicos de Alicún (Depresión de Guadix, Granada, S. EspaÔa)", Geogaceta, 28, pp.35-38.

ESPINAR MORENO, M. (1987a): "El reparto de las aguas del rió Alhama de Guadix en el siglo XIl", Estudios sobre Málaga y el Reino de Granada en el V Centenario de la Conquista, Málaga, pp. 235-255.

ESPINAR MORENO, M. (1987b): "El dominio del agua de riego y las luchas entre varias alquerías de las tierras de Guadix, ss. XII-XVI", Homenaje al Profesor Juan Torres Fontes, Murcia, vol. I, pp. 421-430.

FERNÁNDEZ MÉNDEZ, P. (1998):"El acuífero de Guadix y su relación con la explotación de las Minas de Alquife", Boletín del instituto de Estudios Pedro Suárez n II, pp. 25-42.

GOBLOT, H. (1979): Les qanats. Une technique d'acquisition de l'eau. Paris-La Haye- New York.

LAGARDÈRE, V. (1988-89): "Droit des eaux et des installations hydrauliques au Maghreb et en al-Andalus aux Xlème et Xllème $s$. dans le Mi'yar d'Al Wanšarīisi', Les Cahiers de Tunisie, n |45- | 48, T. XXXVII- XXXVIII, pp. 84- 124.

GÓMEZ CRUZ, M. (1989): "Las ordenanzas de riego de Almería", El Agua en zonas áridas. Arqueología e Historia. Coloquio de Historia y Medio Físico, Almería., pp. I $103-$ I341.

LOISY, P. y MEDINA, F. (1992): "El caso de las minas del Marquesado (C.A.M.)", Jornadas sobre Tecnología del Agua en la Minería, I.T.G.E.

LÓPEZ ANDRÉS, J. y MARTÍN-CARO SAURA, F. (1989): "Organización, distribución y problemas derivados de la administración del agua en Almería y su vega en los aÔos anteriores a la Reconquista", El Agua en zonas áridas. Arqueología e Historia. I Coloquio de Historia y Medio Físico, Almería, pp. 1019-1032.

MARTÍNEZ SAN PEDRO, M. (1989): "Distribución de la tierra y del agua en la comarca almeriense a la salida de los moriscos", El Agua en zonas áridas. Arqueología e Historia. I Coloquio de Historia y Medio Físico, Almería., pp. 1045- 1053

MOLINA LÓPEZ, E. (|99|): "El documento árabe de Guadix (s. XII)", Homenaje al Prof. Jacinto Bosch Vila, I, Univ. de Granada, pp.27I-292

GONZÁLEZTAPIA, J.A. (1988): "Estudio Hidrogeológico y geofísico en el sector del Río Alhama". Informe inédito.

SÁNCHEZ GÓMEZ, M. (2000): Benalúa, historia de un pueblo de la Accitania, Benalúa.

SANTERO SATURNINO, J. (1975): "Una villa tardoromana en Paulenca (Guadix)", Noticiario Arqueológico Hispánico, 3, pp. 227-249.

SEGURA DEL PINO, M. D. (1995):"Las fuentes de Alhadra. Abastecimiento urbano y regadío en la Almería musulmana y morisca", in Agricultura y regadío en Al-Andalus, Almería, pp. 453-463. 


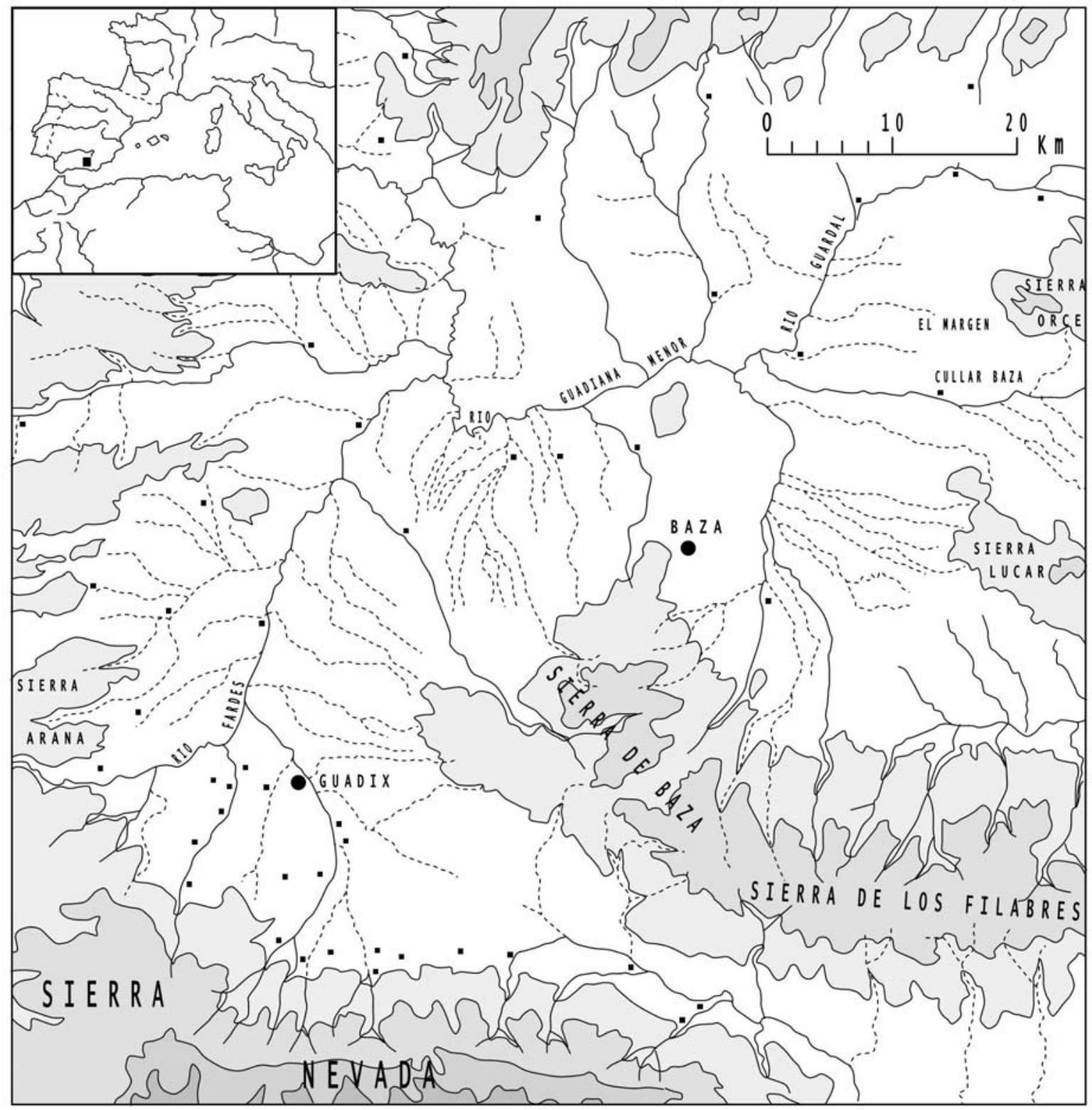

Fig. I. Plano de situación de la depresión de Guadix-Baza. 


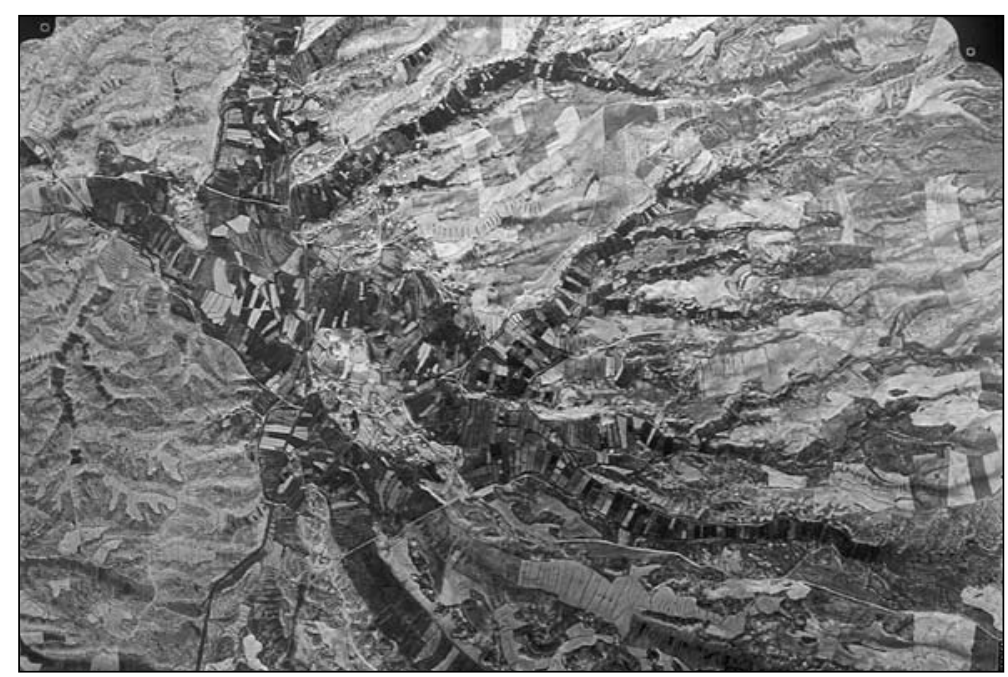

Fig. 2. Territorio de El Margen, compuesto por una serie de largas cañadas regadas con qanats.

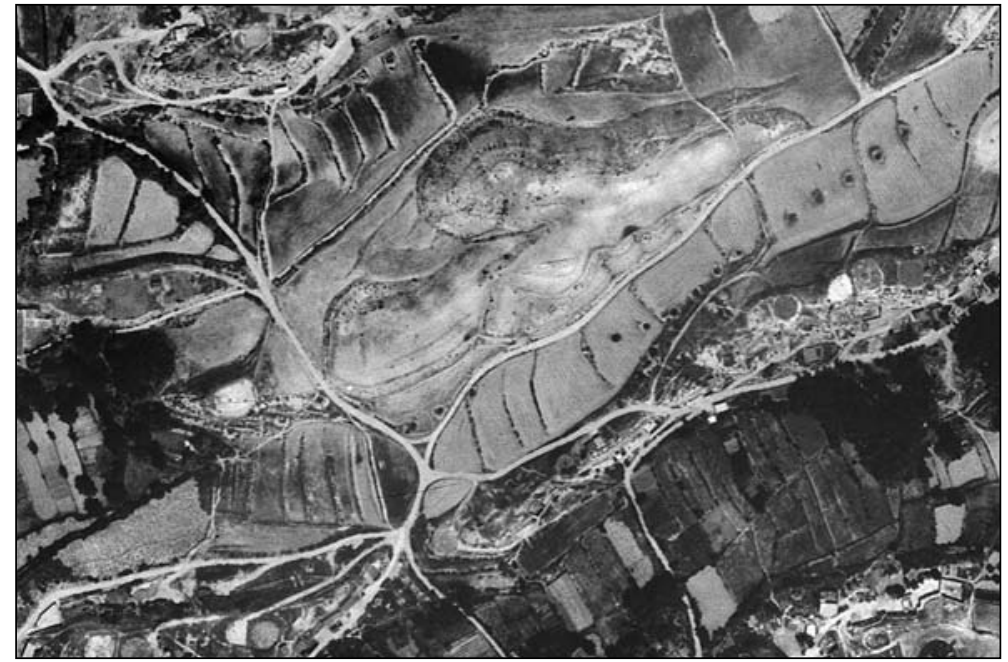

Fig. 3. Canalizo de El Margen.

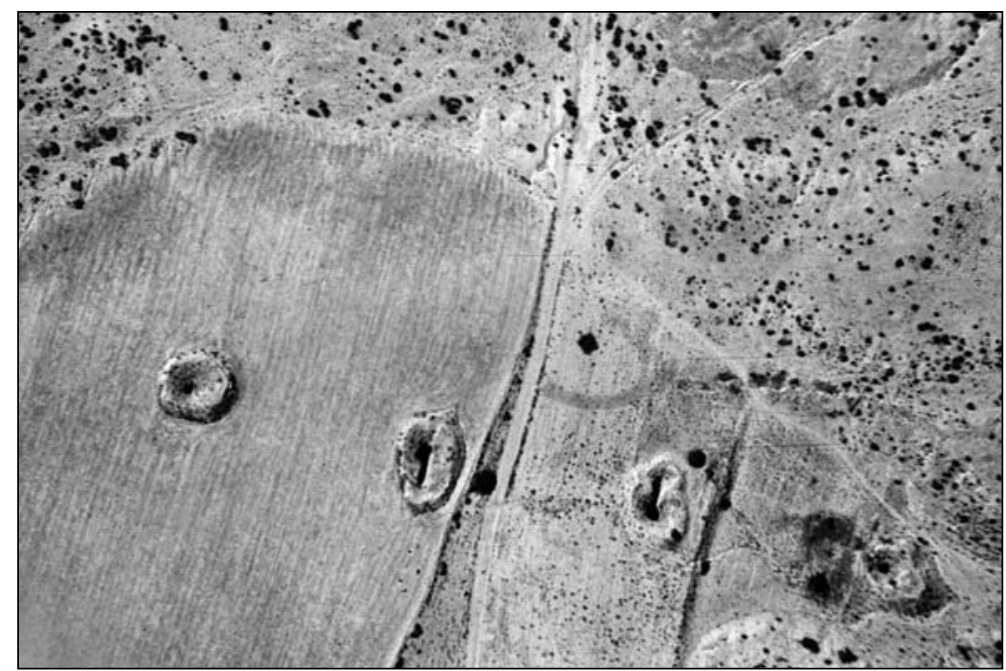

Fig. 4. Pozos de qanat de la zona de Baza. Foto A. Humbert. 


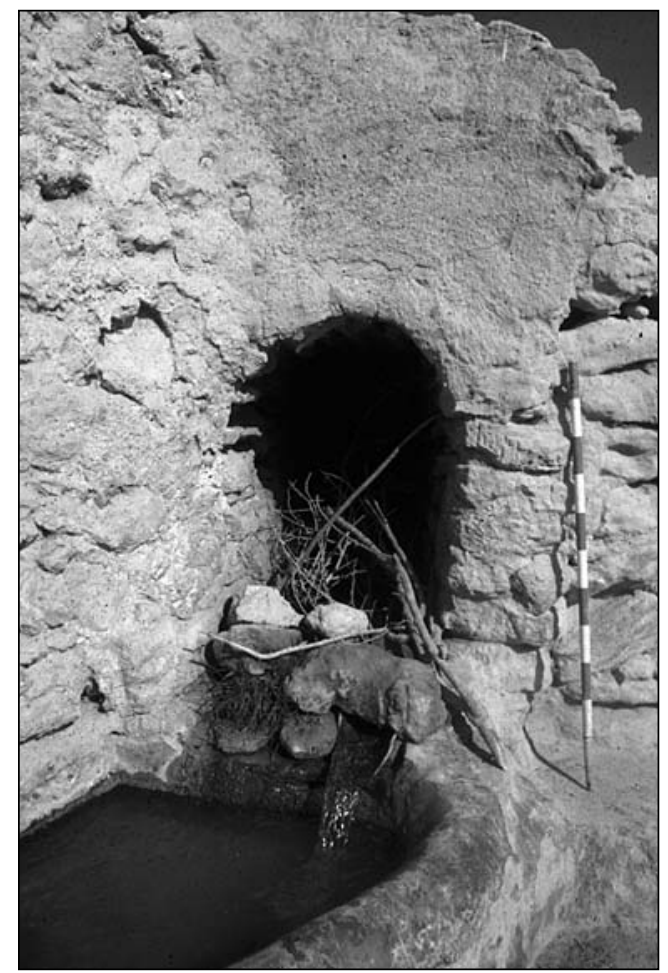

Fig. 5. Canalizo de Soriano.

Fig. 6. Canalizo de Soriano, pozo de aireación.
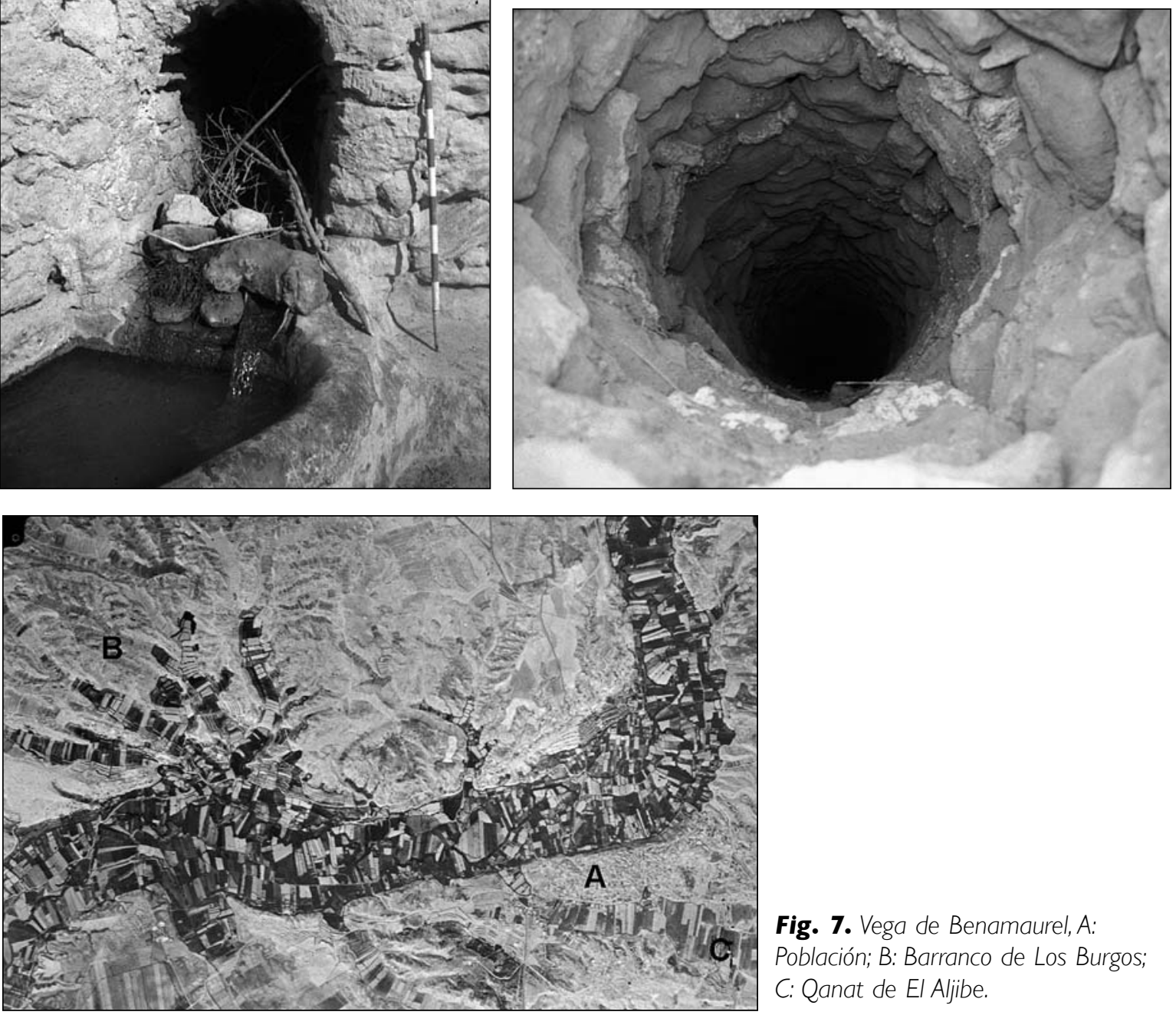

Fig. 7. Vega de Benamaurel, $A$ :

Población; B: Barranco de Los Burgos; C: Qanat de El Aljibe.

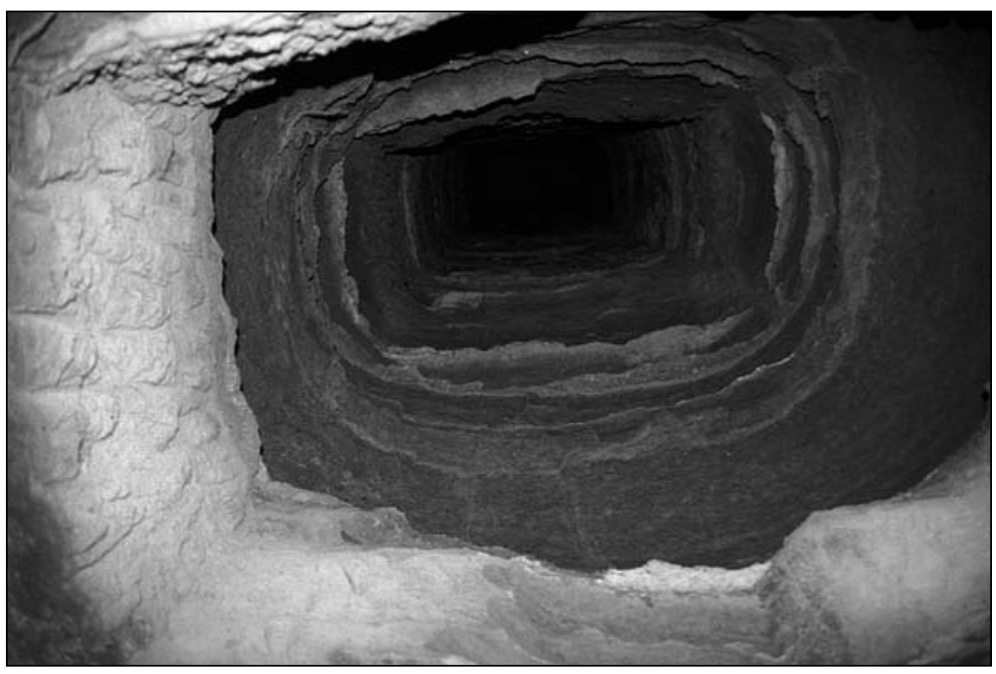

Fig. 8. Pozo de la acequia subterránea de Rasmal, en comunicación con las cuevas acantiladas medievales. 


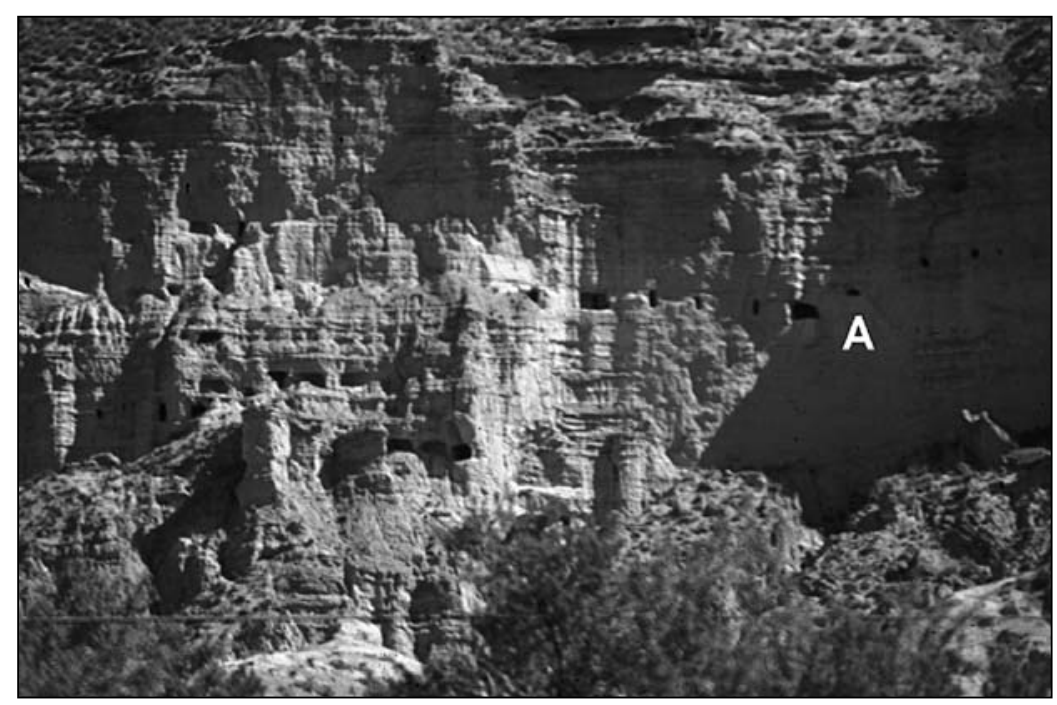

Fig. 9. Cuevas almohades de Los Algarbes, Gorafe, A: acequia.

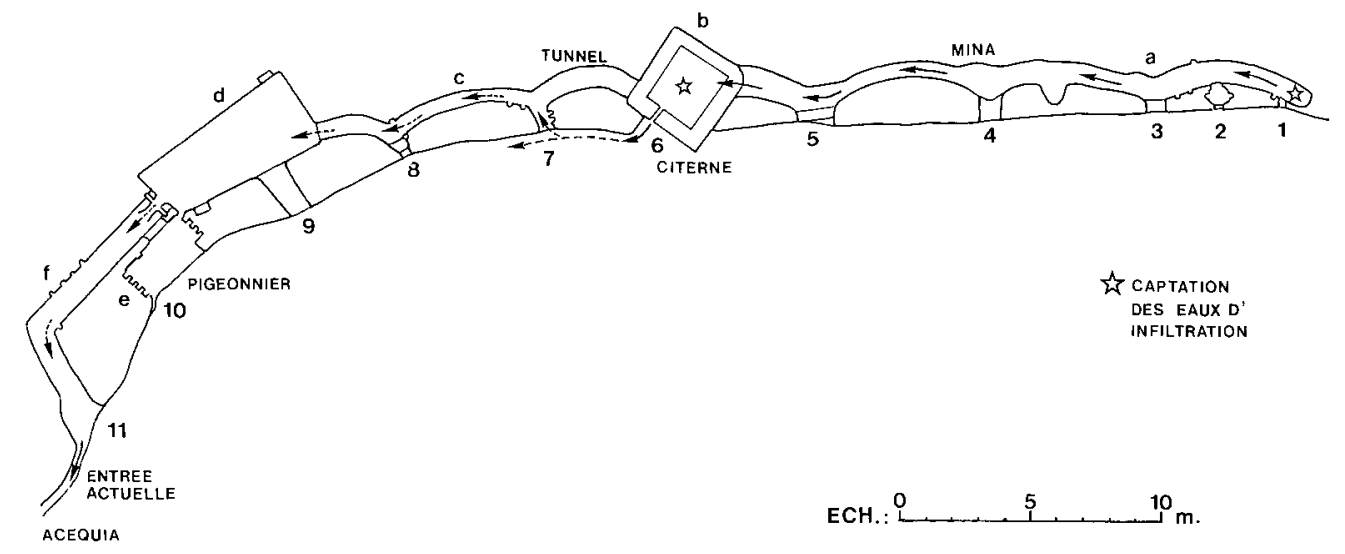

Fig. I 0. Sistema de captación y conducción subterránea colgada de Los Algarbes, Gorafe.

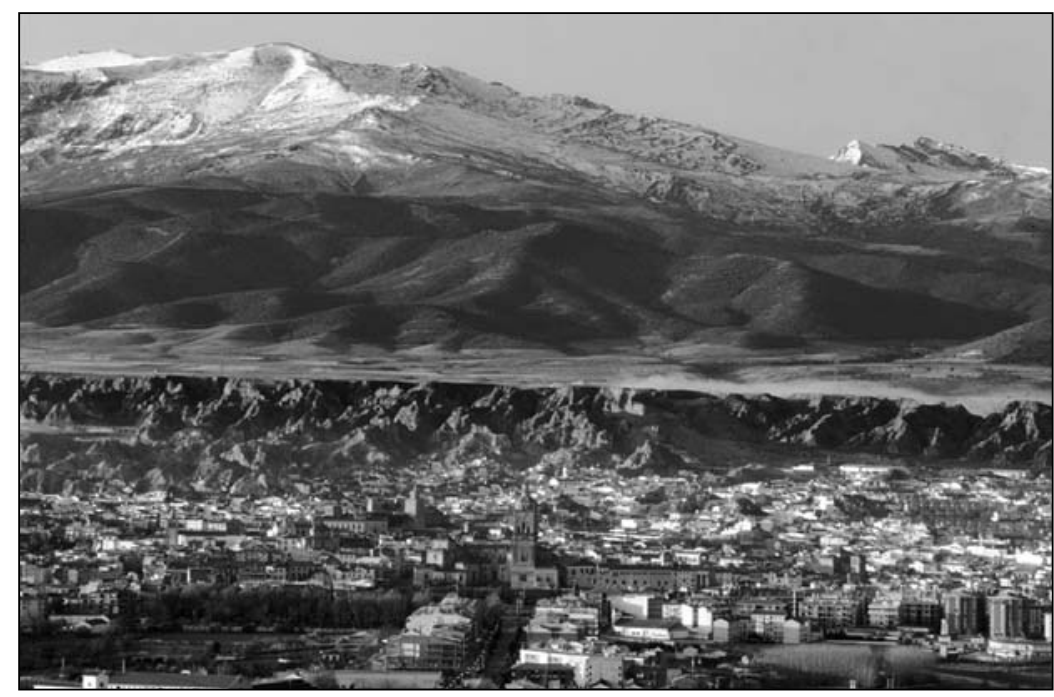

Fig. I I. Escalonamiento de paisajes de la Hoya de Guadix: Sierra Nevada, pie de monte, altiplanicie y tierras bajas, donde se sitúa la ciudad de Guadix. 


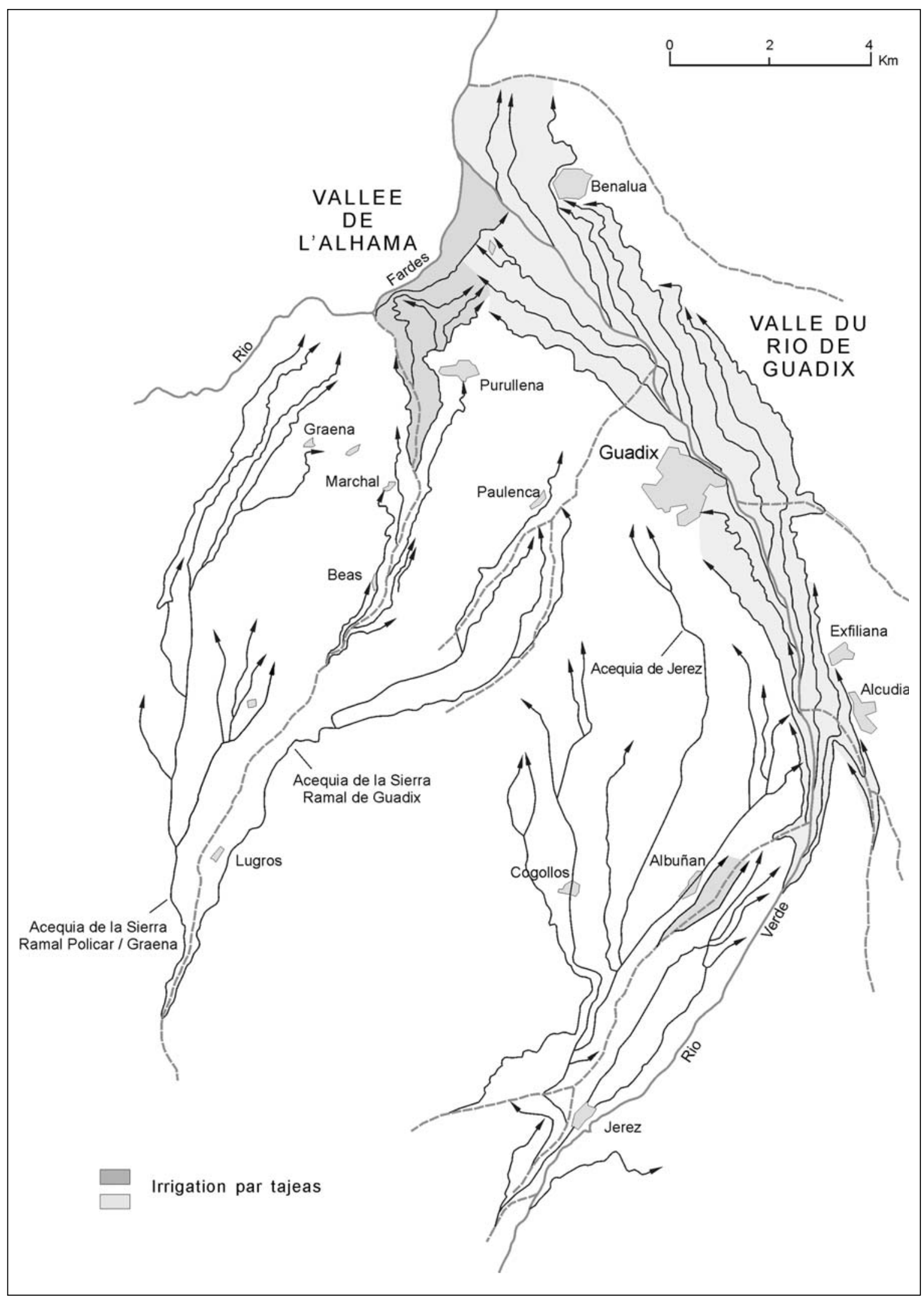

Fig. I 2. Principales sistemas de regadío de la altiplanicie y de la vega de Guadix. 


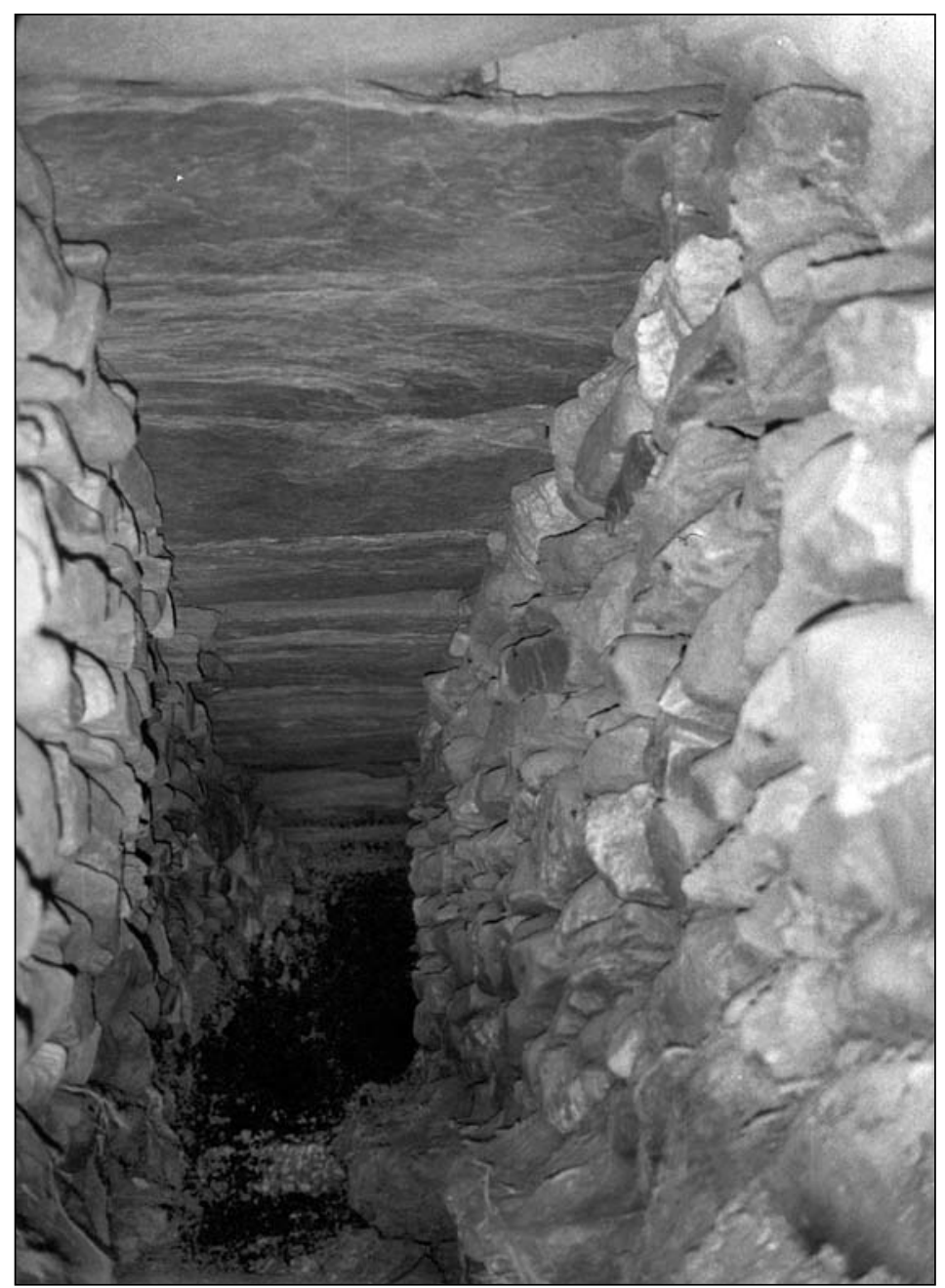

Fig. I 3. Tajea de El Algarabejo, cubierta con lajas de pizarra.

Fig. 14. Tajea abovedada de la Acequia de Chiribaiyle.

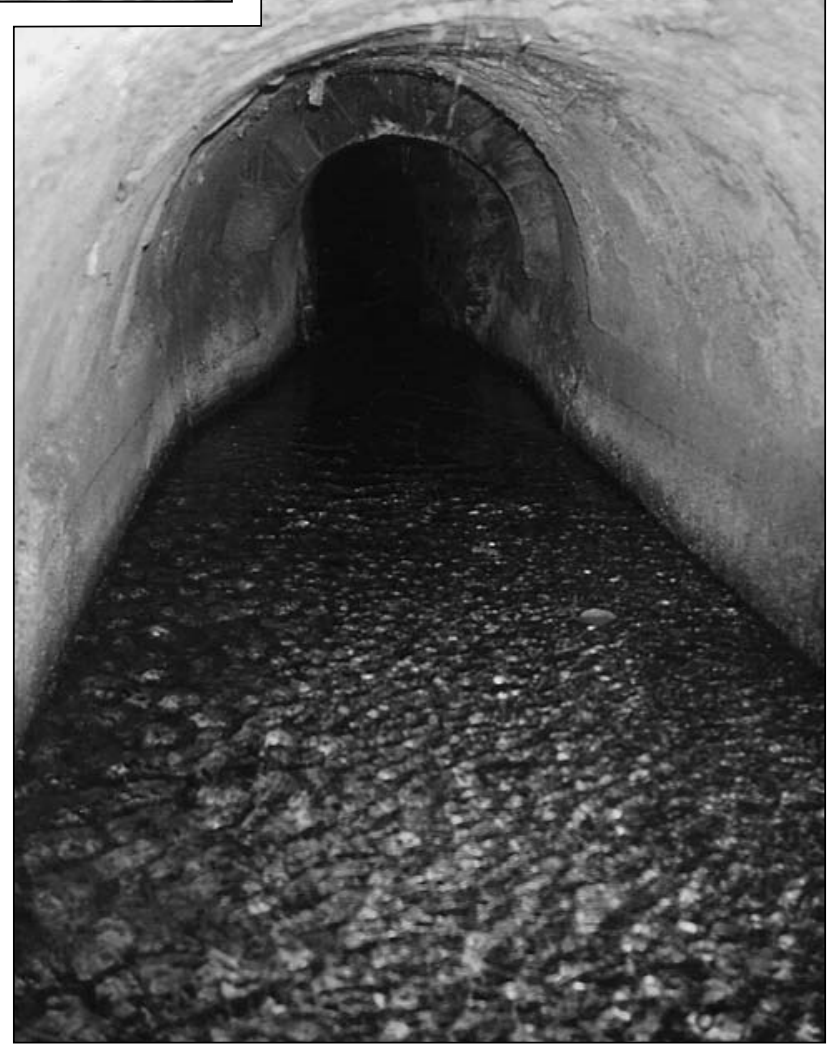




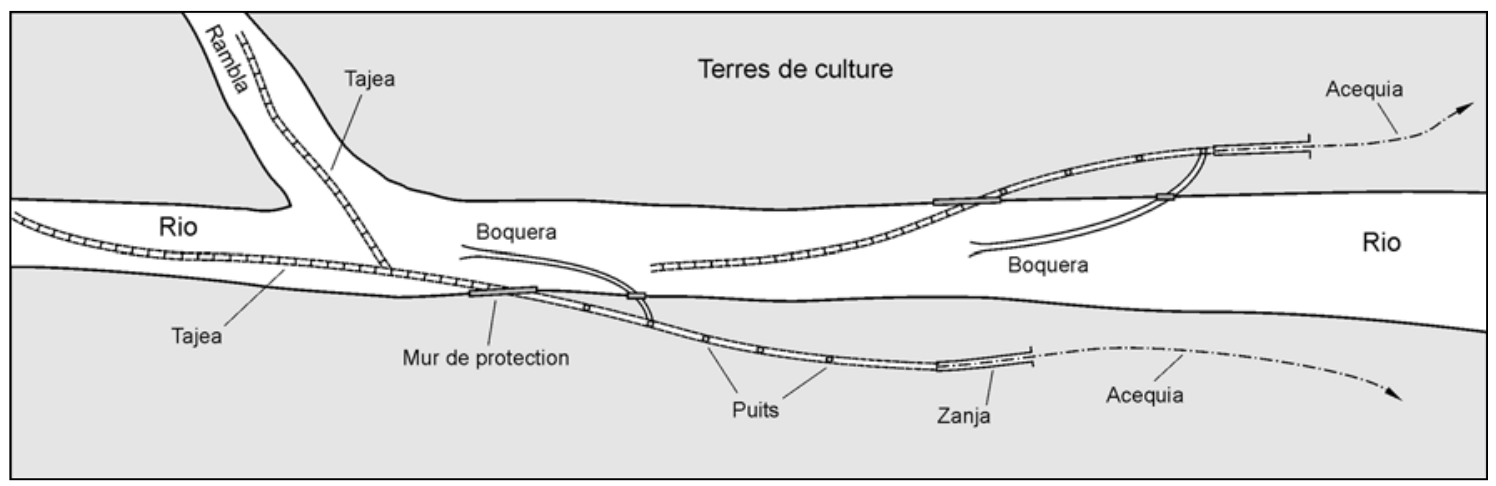

Fig. I5. Esquema de sucesión de tajeas en el valle de Guadix.

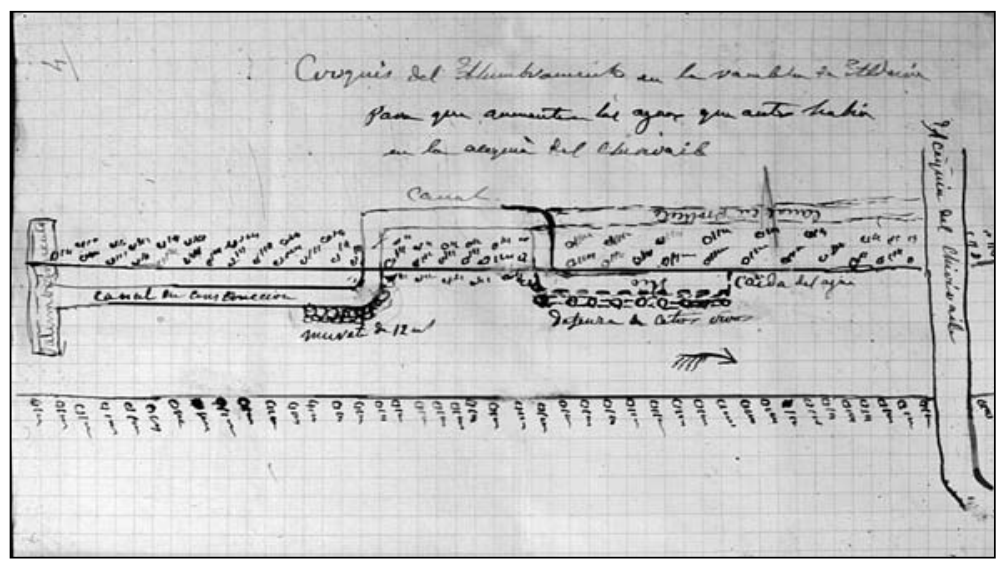

Fig. I6. Proyecto de

construcción de la tajea de la Rambla de Aldeire.

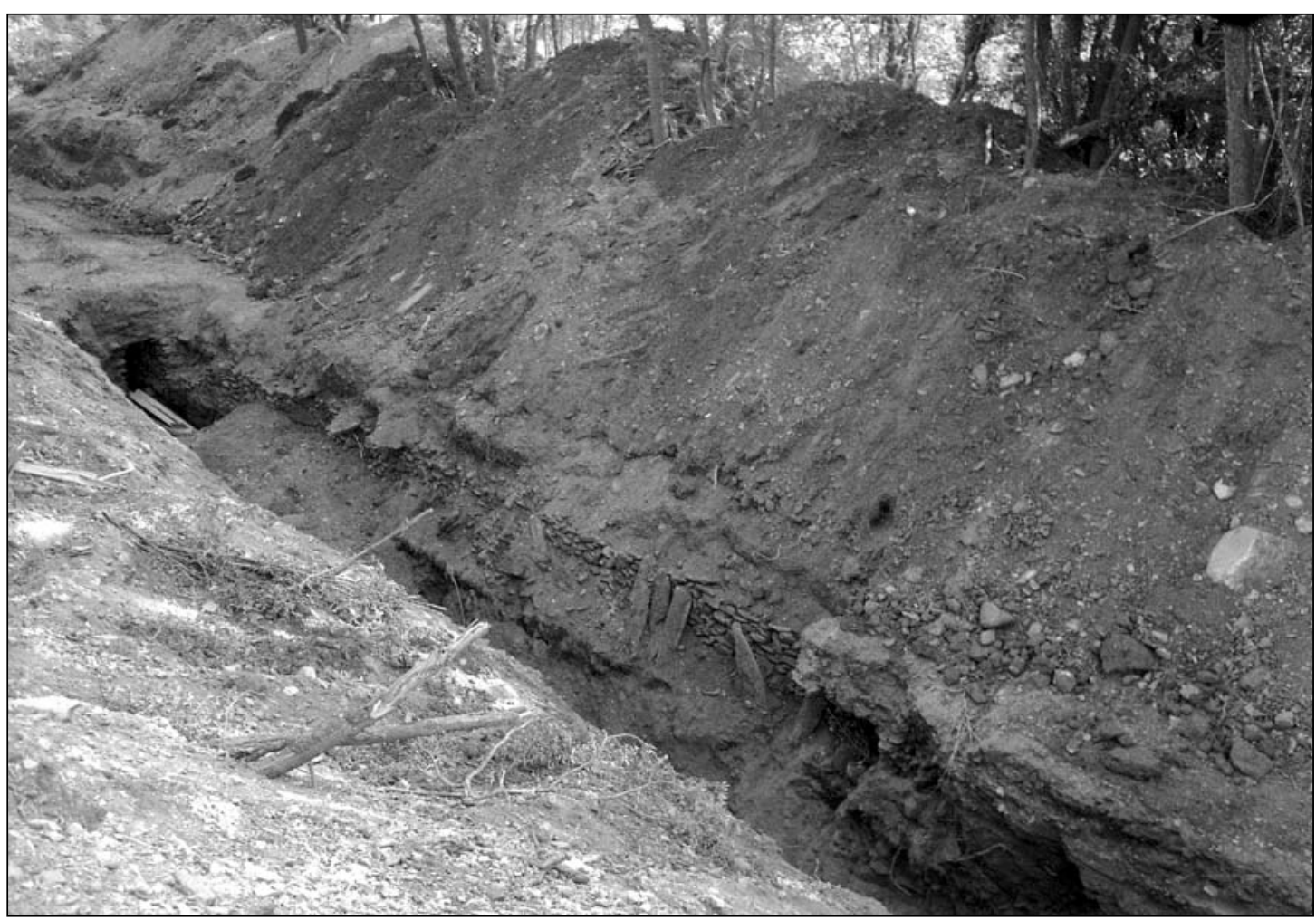

Fig. I 7. Descubierta y destrucción de la tajea de El Algarabejo, en estado de funcionamiento... 


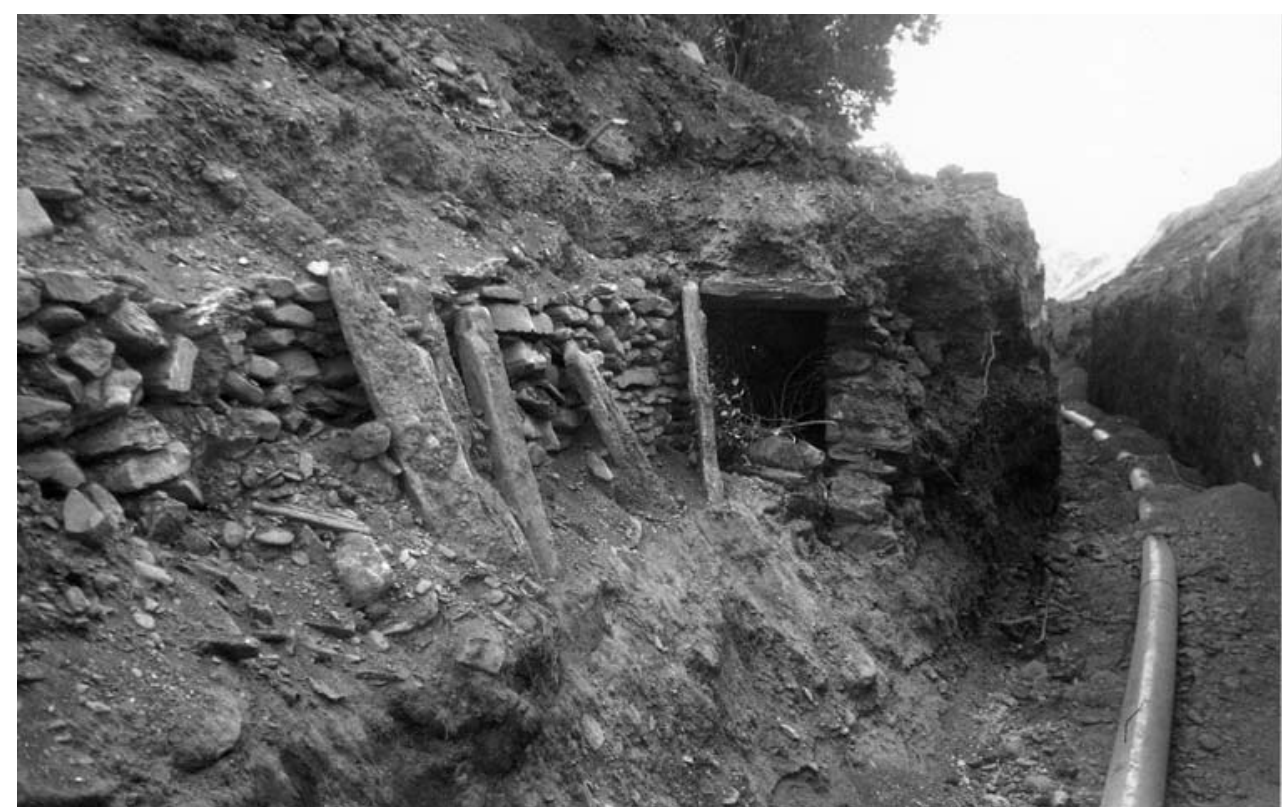

Fig. I 8. ... para remplazarla con un sistema de tubos de plástico hoy día completamente atorados.

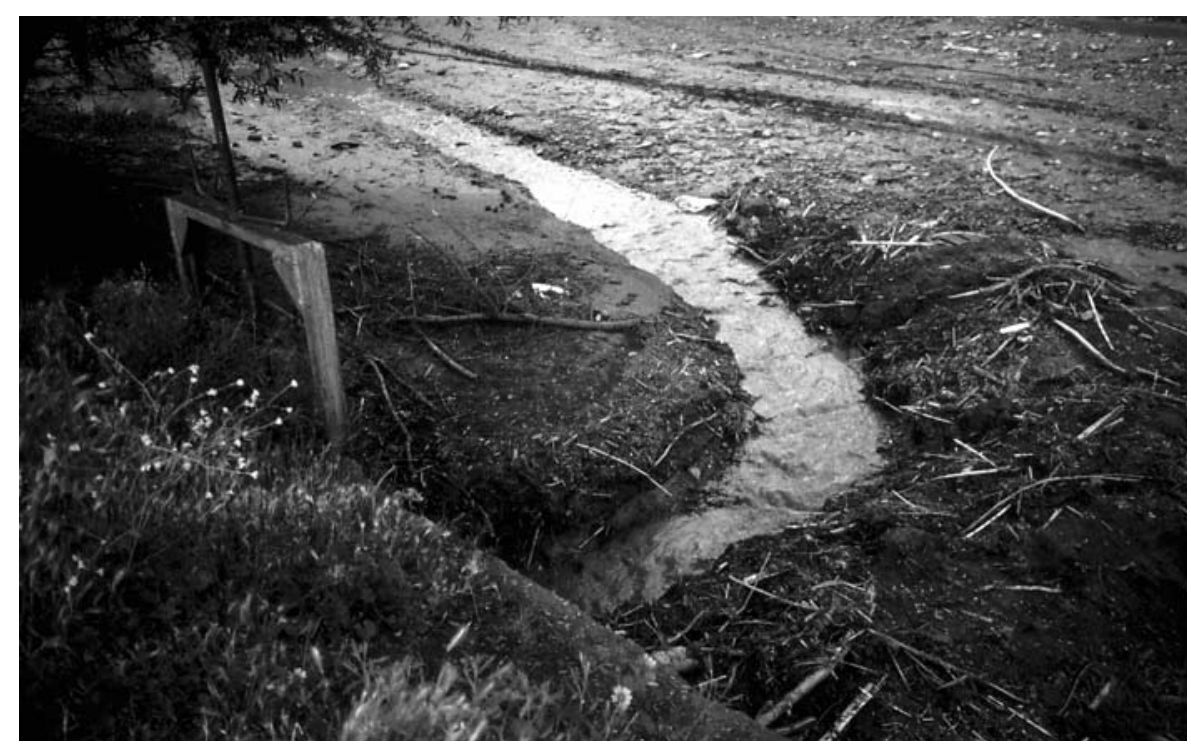

Fig. 19. Boquera de la Acequia de Almecín tras una tormenta.

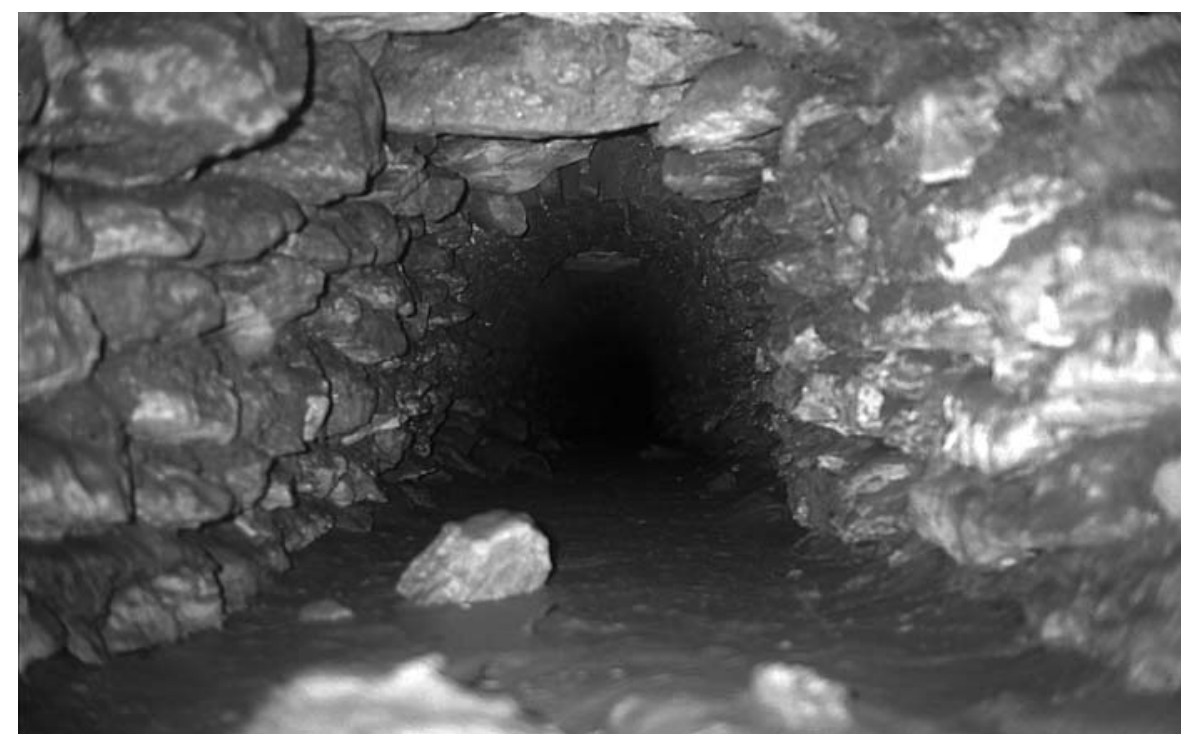

Fig. 20. Tajea col-

matada del molino de Peñuela. 


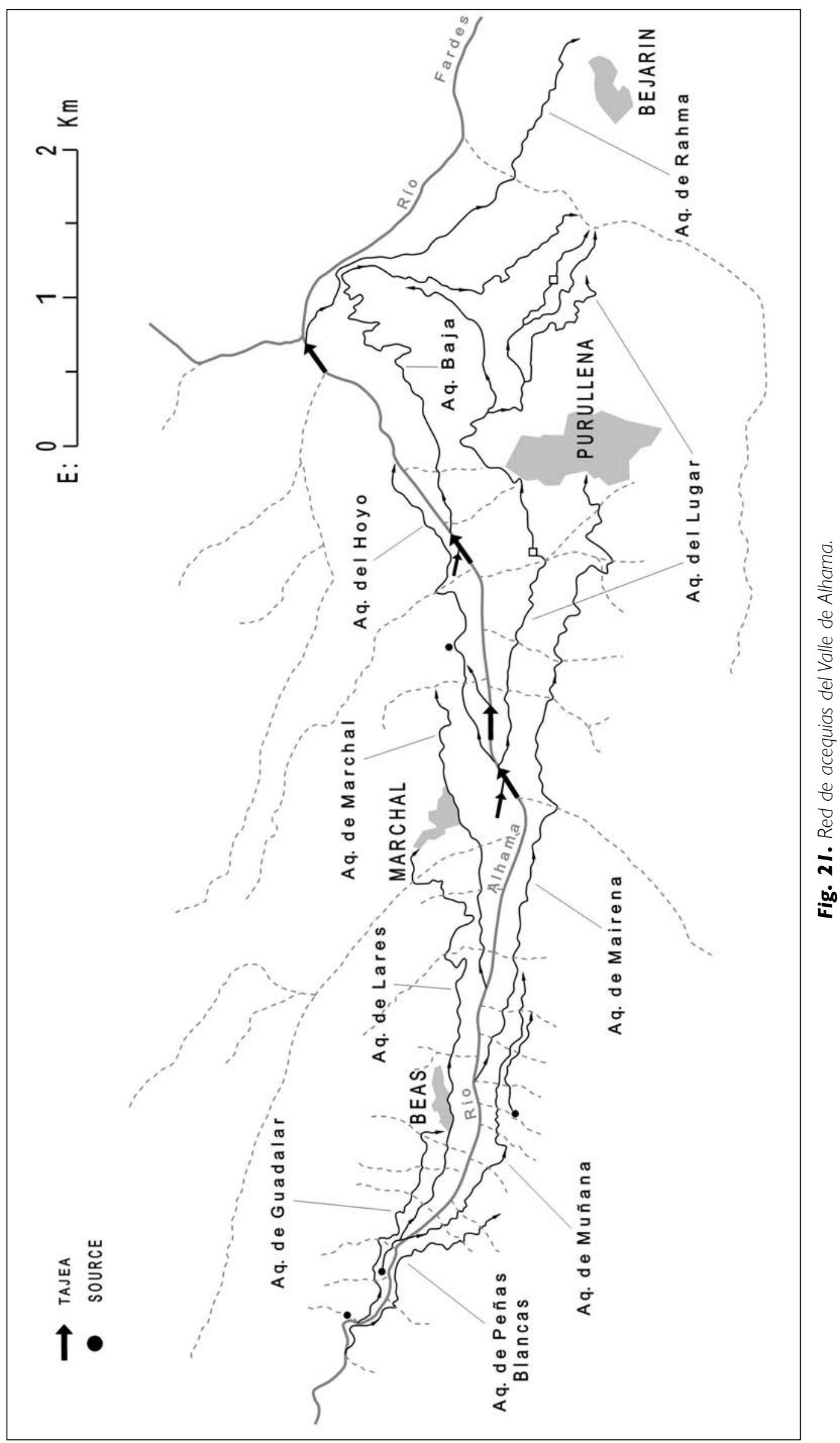




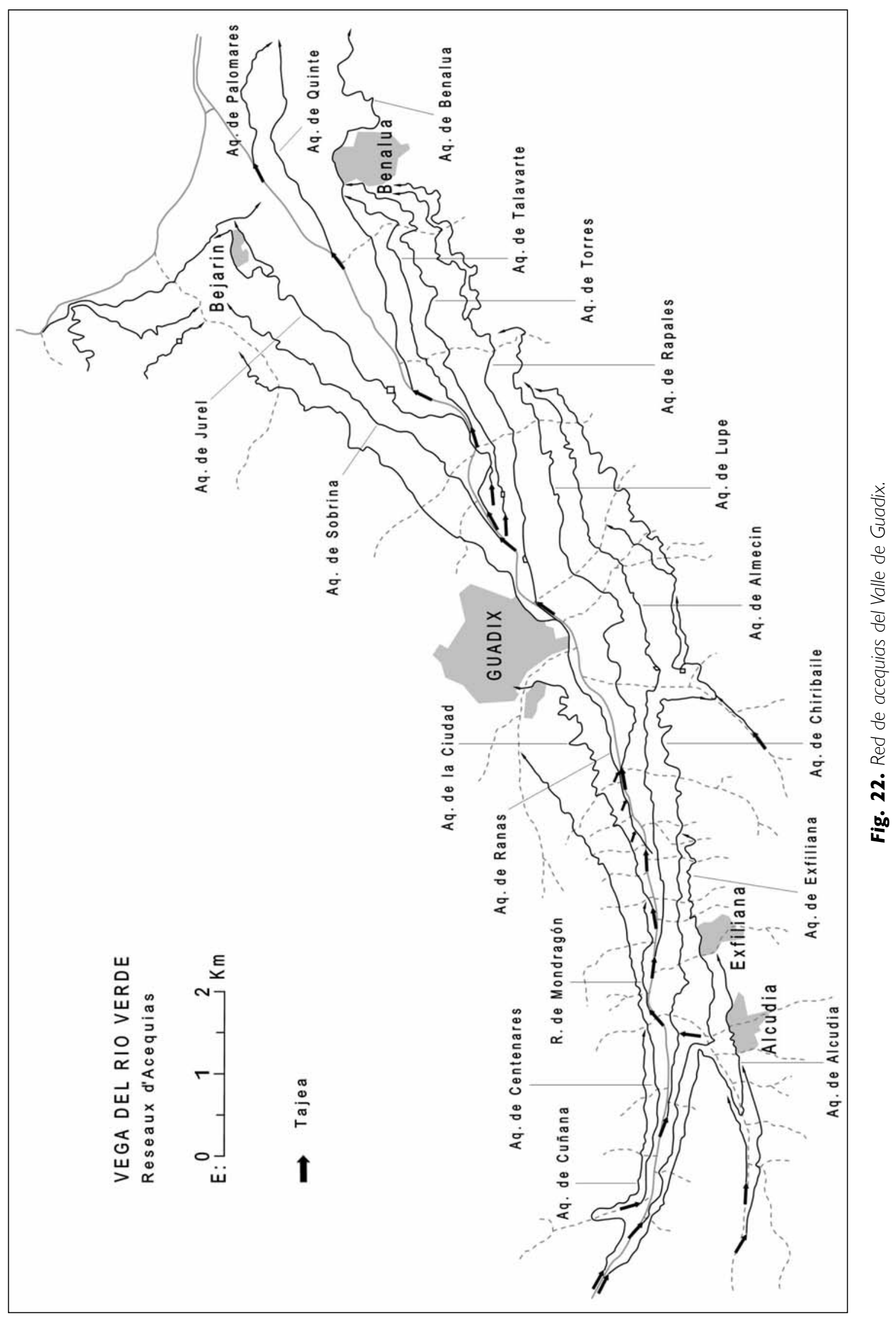




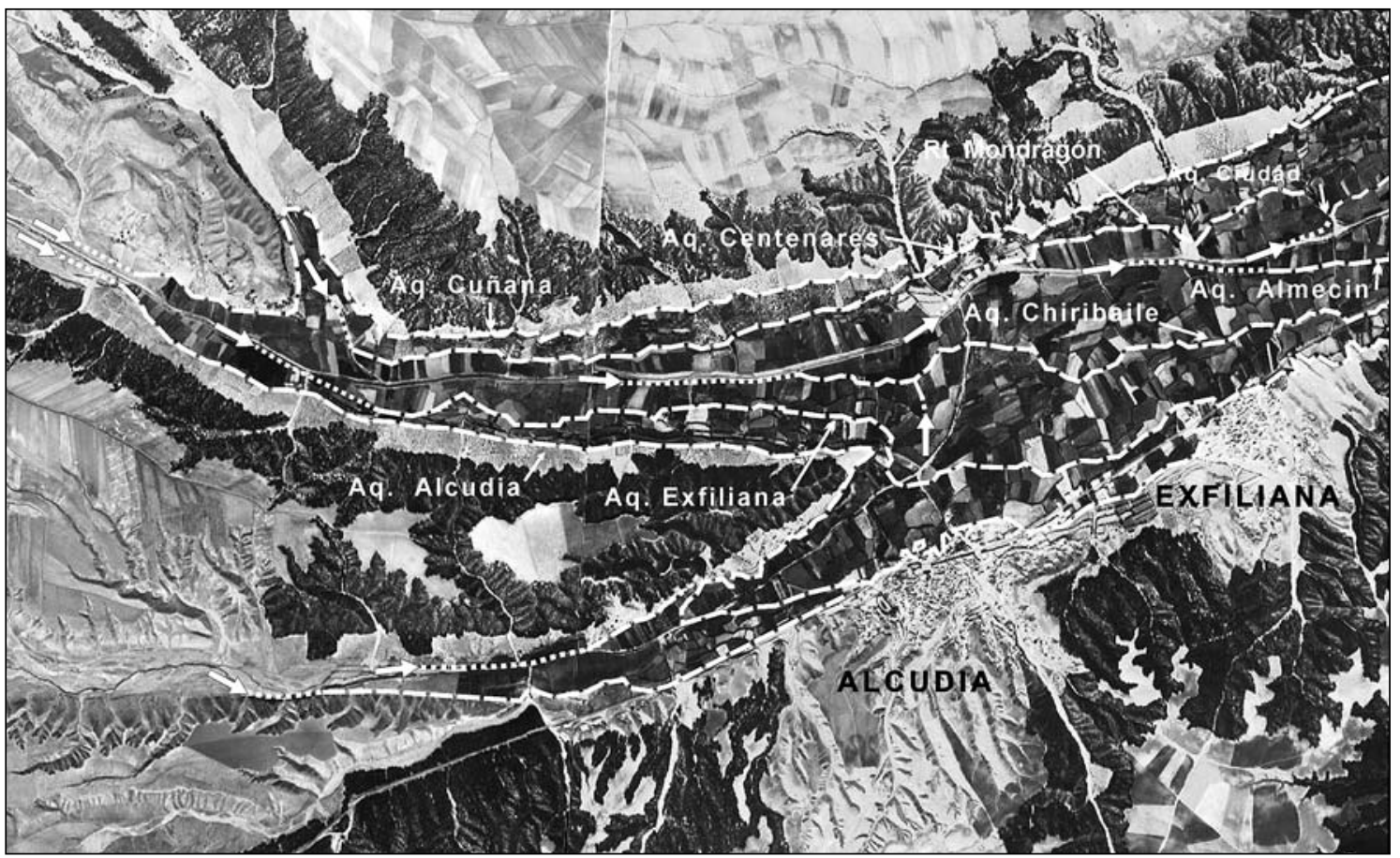

Fig. 23. Tajeas de la zona alta del Valle de Guadix (Alcudia y Esfiliana).
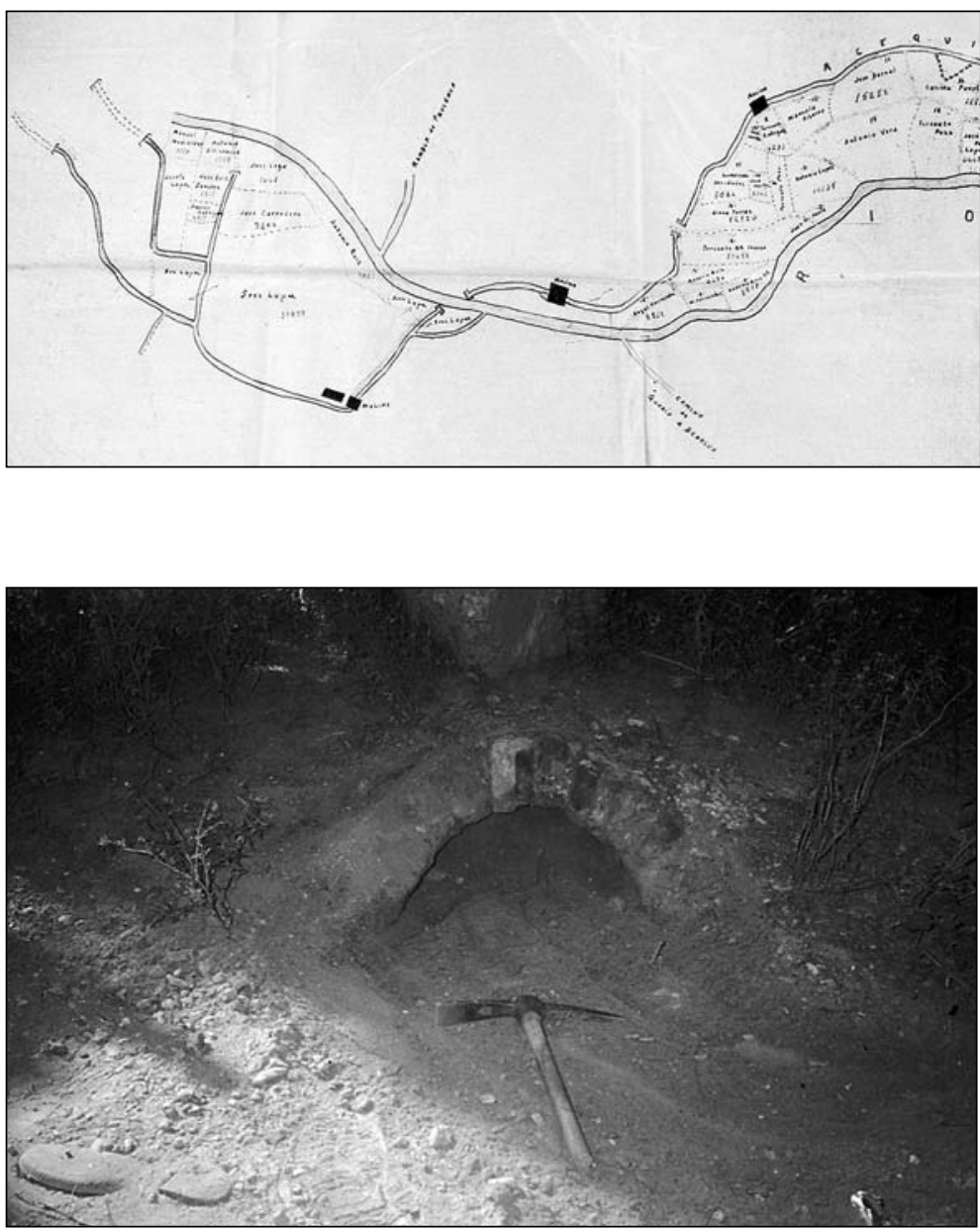

Fig. 24. Planimetría antigua de las captaciones de la Acequia de Jurel (Archivo de la Comunidad de Regantes de la Acequia de Jurel).

Fig. 25. Antigua tajea, abovedada con ladrillos, localizada en la orilla del Río de Guadix (Molino de Los Guindos). 


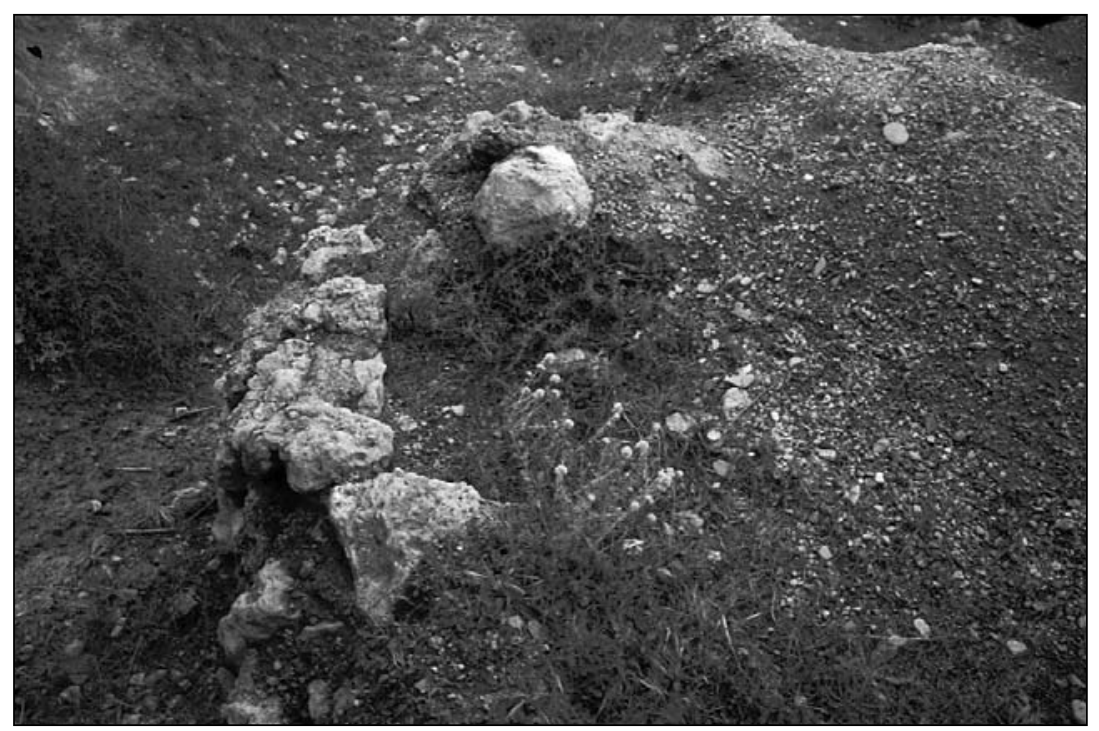

Fig. 26. Pozos de una antigua tajea en la Rambla de Fiñana. 